\title{
Performance measures for small-bowel endoscopy: a European Society of Gastrointestinal Endoscopy (ESGE) Quality Improvement Initiative
}

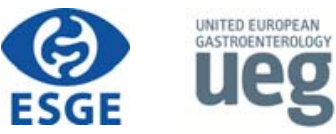

Authors

Cristiano Spada ${ }^{1,2}$, Deirdre McNamara ${ }^{3}$, Edward J. Despott ${ }^{4}$, Samuel Adler ${ }^{5}$, Brooks D. Cash ${ }^{6,7}$, Ignacio FernándezUrién $^{8}$, Hrvoje Ivekovic ${ }^{9}$, Martin Keuchel ${ }^{10}$, Mark McAlindon ${ }^{11}$, Jean-Christophe Saurin ${ }^{12}$, Simon Panter ${ }^{13}$, Cristina Bellisario $^{14}$, Silvia Minozzi ${ }^{14}$, Carlo Senore ${ }^{14}$, Cathy Bennett ${ }^{15}$, Michael Bretthauer ${ }^{16}$, Mario Dinis-Ribeiro ${ }^{17}$, Dirk Domagk $^{18}$, Cesare Hassan ${ }^{19}$, Michal F. Kaminski ${ }^{20,21,22}$, Colin J. Rees ${ }^{23}$, Roland Valori' ${ }^{24}$, Raf Bisschops ${ }^{25}$, Matthew D. Rutter ${ }^{23,26}$

\section{Institutions}

1 Digestive Endoscopy Unit and Gastroenterology, Fondazione Poliambulanza, Brescia, Italy

2 Digestive Endoscopy Unit, Fondazione Policlinico Universitario A. Gemelli - IRCCS, Rome, Italy

3 TAGG Research Centre, Department of Clinical Medicine, Tallaght Hospital, Trinity College Dublin, Ireland

4 Royal Free Unit for Endoscopy, The Royal Free Hospital and UCL Institute for Liver and Digestive Health, London, UK

5 Division of Gastroenterology, Shaare Zedek Medical Center, Jerusalem, Israel

6 Department of Gastroenterology, Hepatology, and Nutrition, UT Health Science Center at Houston/ Memorial Hermann, Houston, USA

7 McGovern Medical School, Department of Internal Medicine, Houston, USA

8 Department of Gastroenterology, Navarra Hospital Complex, Pamplona, Spain

9 Department of Gastroenterology and Hepatology, University Hospital Centre, Zagreb, Croatia

10 Clinic for Internal Medicine, Bethesda Krankenhaus Bergedorf, Hamburg, Germany

11 Academic Department of Gastroenterology and Hepatology, Sheffield Teaching Hospitals NHS Trust, Sheffield, UK

12 Gastroenterology and Endoscopy Unit, Hospices Civils de Lyon, Hôpital E. Herriot, Lyon, France

13 Department of Gastroenterology, South Tyneside NHS Foundation Trust, South Shields, UK

14 CPO Piemonte, AOU Città della Salute e della Scienza, Turin, Italy

15 Office of Research and Innovation, Royal College of Surgeons in Ireland Coláiste Ríoga na Máinleá in Éirinn, Dublin, Ireland
16 Clinical Effectiveness Research Group, University of Oslo and Oslo University Hospital, Oslo, Norway

17 Servicio de Gastroenterologia, Instituto Portugues de Oncologia Francisco Gentil, Porto, Portugal

18 Department of Medicine I, Josephs-Hospital Warendorf, Academic Teaching Hospital, University of Muenster, Warendorf, Germany

19 Endoscopy Unit, Nuovo Regina Margherita Hospital, Rome, Italy

20 Department of Gastroenterology, Hepatology and Oncology, Medical Center for Postgraduate Education, Warsaw, Poland

21 Department of Gastroenterological Oncology and Department of Cancer Prevention, The Maria Sklodowska-Curie Memorial Cancer Center and Institute of Oncology, Warsaw, Poland

22 Department of Health Management and Health Economics, University of Oslo, Oslo, Norway

23 Northern Institute for Cancer Research, Newcastle University, Newcastle, UK

24 Department of Gastroenterology, Gloucestershire Hospitals NHS Foundation Trust, Gloucestershire, UK

25 Department of Gastroenterology and Hepatology. University Hospital Leuven, Leuven, Belgium

26 Department of Gastroenterology, University Hospital of North Tees, Stockton-on-Tees, Cleveland, UK

Bibliography

DOI https://doi.org/10.1055/a-0889-9586

Published online: 10.5.2019 | Endoscopy 2019; 51: 574-598

(c) Georg Thieme Verlag KG Stuttgart · New York

ISSN 0013-726X 
Corresponding author

Cristiano Spada, MD, Fondazione Poliambulanza, Via L.

Bissolati, 57, 25124 Brescia, Italy

cristiano.spada@poliambulanza.it

\section{ABSTRACT}

The European Society of Gastrointestinal Endoscopy (ESGE) together with the United European Gastroenterology (UEG) recently developed a short list of performance measures for small-bowel endoscopy (i.e. small-bowel capsule endoscopy and device-assisted enteroscopy) with the final goal of providing endoscopy services across Europe with a tool for quality improvement. Six key performance measures for both small-bowel capsule endoscopy and for device-assisted enteroscopy were selected for inclusion, with the intention being that practice at both a service and endoscopist level should be evaluated against them. Other performance measures were considered to be less relevant, based on an assessment of their overall importance, scientific acceptability, and feasibility. Unlike lower and upper gastrointestinal endoscopy, where performance measures had already been identified, this is the first time that small-bowel endoscopy quality measures have been proposed.

\section{PUBLICATION INFORMATION}

This article is published simultaneously in the journals Endoscopy and United European Gastroenterology journal. Copyright 2019 @ Georg Thieme Verlag KG and ( ) by the United European Gastroenterology.

\section{Introduction}

The European Society of Gastrointestinal Endoscopy (ESGE) and United European Gastroenterology (UEG) have identified the need to benchmark the quality of endoscopic procedures as a high priority. The rationale for this was recently described in a manuscript that also addressed the methodology of the current quality initiative process [1].

The identification of small-bowel endoscopy performance measures presents several challenges, in contrast to the situation with upper and lower gastrointestinal (GI) endoscopy, where several performance measures have been identified over recent years. To date, a specific set of quality measures for small-bowel endoscopy that could serve as a basis for quality assessment and improvement has not been produced. Moreover, in contrast to upper and lower GI endoscopy, smallbowel endoscopy encompasses two distinct modalities as the small bowel can be approached by means of a non-invasive, diagnostic modality (i.e. small-bowel capsule endoscopy [SBCE]) and/or a more invasive, diagnostic, and therapeutic modality (i.e. device-assisted enteroscopy [DAE]). Although SBCE and DAE target the same organ, they differ greatly in terms of technique, procedure, process, and outcome.

The aim of the ESGE small-bowel working group was to identify a short list of performance measures for small-bowel endoscopy that were widely applicable to endoscopy services across Europe. Performance measures refer to specific issues identified for comparison and potential improvement and they represent the minimal acceptable standard of care. This list would ideally consist of performance measures with the following characteristics: proven impact on significant clinical outcomes or quality of life; a well-defined, reliable, and simple

\begin{tabular}{|c|c|}
\hline \multicolumn{2}{|c|}{ ABBREVIATIONS } \\
\hline ASGE & American Society for Gastrointestinal Endoscopy \\
\hline CEST & capsule endoscopy structured terminology \\
\hline $\mathrm{Cl}$ & confidence interval \\
\hline DAE & device-assisted enteroscopy \\
\hline DBE & double-balloon enteroscopy \\
\hline ERCP & $\begin{array}{l}\text { endoscopic retrograde cholangiopancreatogra- } \\
\text { phy }\end{array}$ \\
\hline ESGE & European Society of Gastrointestinal Endoscopy \\
\hline Gl & gastrointestinal \\
\hline GRADE & $\begin{array}{l}\text { Grading of Recommendations Assessment, } \\
\text { Development and Evaluation }\end{array}$ \\
\hline GRS & Global Rating Scale \\
\hline IBD & inflammatory bowel disease \\
\hline ISFU & $\begin{array}{l}\text { Importance, Scientific acceptability, Feasibility, } \\
\text { Usability }\end{array}$ \\
\hline NSAID & nonsteroidal anti-inflammatory drug \\
\hline PICO & $\begin{array}{l}\text { Population/Patient, Intervention/Indicator, } \\
\text { Comparator/Control, Outcome }\end{array}$ \\
\hline RCT & randomized controlled trial \\
\hline SBCE & small-bowel capsule endoscopy \\
\hline SBE & single-balloon enteroscopy \\
\hline UEG & United European Gastroenterology \\
\hline VAS & visual analogue scale \\
\hline
\end{tabular}

method for measurement; opportunity for improvement; and application to all levels of endoscopy services.

Bearing in mind the lack of a previous comprehensive peerreviewed paper describing quality measures, the ESGE smallbowel working group evaluated the available evidence and/or absence of evidence in order to identify research priorities. This manuscript reports the agreed list of performance measures for small-bowel endoscopy and describes the methodological process applied in the development of these measures. Performance measures are divided into key performance measures and minor performance measures. The list of performance measures and the methodological process applied in the devel- 
opment of these measures are described separately for SBCE and DAE.

\section{Methodology}

The multistep methodological process used to develop performance measures has previously been described [1]. Briefly, a modified Delphi consensus process was used to develop quality measures in the following domains: pre-procedure, completeness of procedure, identification of pathology, management of pathology, complications, procedure numbers, patient experience, and post-procedure. One or two key performance measures were selected for each quality domain. Minor performance measures, if any, were also described for each domain.

For each of the identified domains, every participant of the ESGE small-bowel working group was invited to identify performance measures. All of the possible performance measures suggested were discussed through email correspondence and teleconferences. All possible performance measures identified by this process were then structured using the PICO framework (where P stands for Population/Patient, I for Intervention/Indicator, C for Comparator/Control, and O for Outcome) to inform searches for any available evidence to support these performance measures. Detailed literature searches were performed by an expert team of methodologists. Working group members also identified additional articles relevant to the performance measures in question.

The PICOs and the clinical statements derived from these were adapted or omitted during iterative rounds of comments and suggestions from the working group members during the Delphi process. In total, working group members participated in a maximum of three rounds of voting to agree on performance measures in the predefined domains and their respective thresholds, as discussed below. A statement was accepted if at least $80 \%$ agreement was reached after a minimum of two voting rounds. Statements not reaching agreement were modified according to the comments made in the voting rounds. Statements were discarded if agreement was not reached over three voting rounds. The agreement given for the different statements refers to the last voting round in the Delphi process (see Supporting Information, available online).

The key performance measures were distinguished from the minor performance measures based on the ISFU criteria (Importance, Scientific acceptability, Feasibility, Usability, and comparison with competing measures), expressed by mean voting scores.

The performance measures are displayed in boxes under the relevant quality domain. Each box describes the performance measure, the level of agreement reached during the modified Delphi process, the grading of available evidence (the evidence was graded according to the Grading of Recommendations Assessment, Development and Evaluation [GRADE] system), how the performance measure should be measured, and recommendations supporting its adoption. The boxes further list the measurement of agreement (scores), the desired threshold, and suggestions on how to deal with underperformance. The minimum number needed to assess whether the threshold for a certain performance measure is reached can be calculated by estimating the $95 \%$ confidence intervals $(\mathrm{Cls})$ around the predefined threshold for different sample sizes. For reasons of practicality and to simplify implementation and auditing, the working group suggested that at least 100 consecutive procedures (or all, if $<100$ were performed) should be measured to assess a given performance measure.

The assessment of performance measures should be applied at an individual level; however, in situations where this is not feasible, assessment of performance measures should at least be applied at a service level. To facilitate service improvement, there should be at least an annual audit of a sufficient number of procedures with appropriate actions taken when suboptimal performance is identified. If the recommended threshold is not reached at a service level, further evaluation at an individual level is required to identify quality constraints and possible action(s) required for improvement.

\section{Small-bowel capsule endoscopy (SBCE)}

To identify performance measures, first a list of all possible performance measures for SBCE was created through email correspondence, teleconference, and face-to-face meetings that took place between May 2015 and October 2015. This process resulted in 29 possible performance measures and 50 PICOs. The performance measures and PICOs were consolidated for consistency and any overlap was limited through email correspondence and teleconferences. After a discussion within the working group, a total of $23 \mathrm{PICO}$ were selected and retained as the basis of the literature searches, performed by a team of expert methodologists.

The evidence derived from the literature searches, along with input from the working group members, generated a total of 38 clinical statements addressing 17 potential performance measures, grouped into eight quality domains. The PICOs and the clinical statements were adapted and/or excluded during the iterative rounds of voting and comments from the working group during the Delphi process. Over the course of three rounds of voting, consensus agreement was reached for 18 statements relating to 10 performance measures. The remaining clinical statements and performance measures did not reach agreement over the course of the three rounds of voting; it was also impossible to define performance measures for three domains (i.e. number of procedures, patient experience, and post-procedure). Therefore, a final total of 10 performance measures (18 statements) attributed to five quality domains were accepted for these guidelines ( $\triangleright$ Fig. 1 ).

\section{Device-assisted enteroscopy}

In order to identify performance measures, first a list of all possible performance measures for DAE was created through email correspondence, teleconference, and face-to-face meetings that took place between March 2016 and February 2017. This process resulted in 34 possible performance measures and 65 PICOs. The performance measures and PICOs were consolidated for consistency and any overlap was limited through email correspondence and teleconferences. After a discussion within 


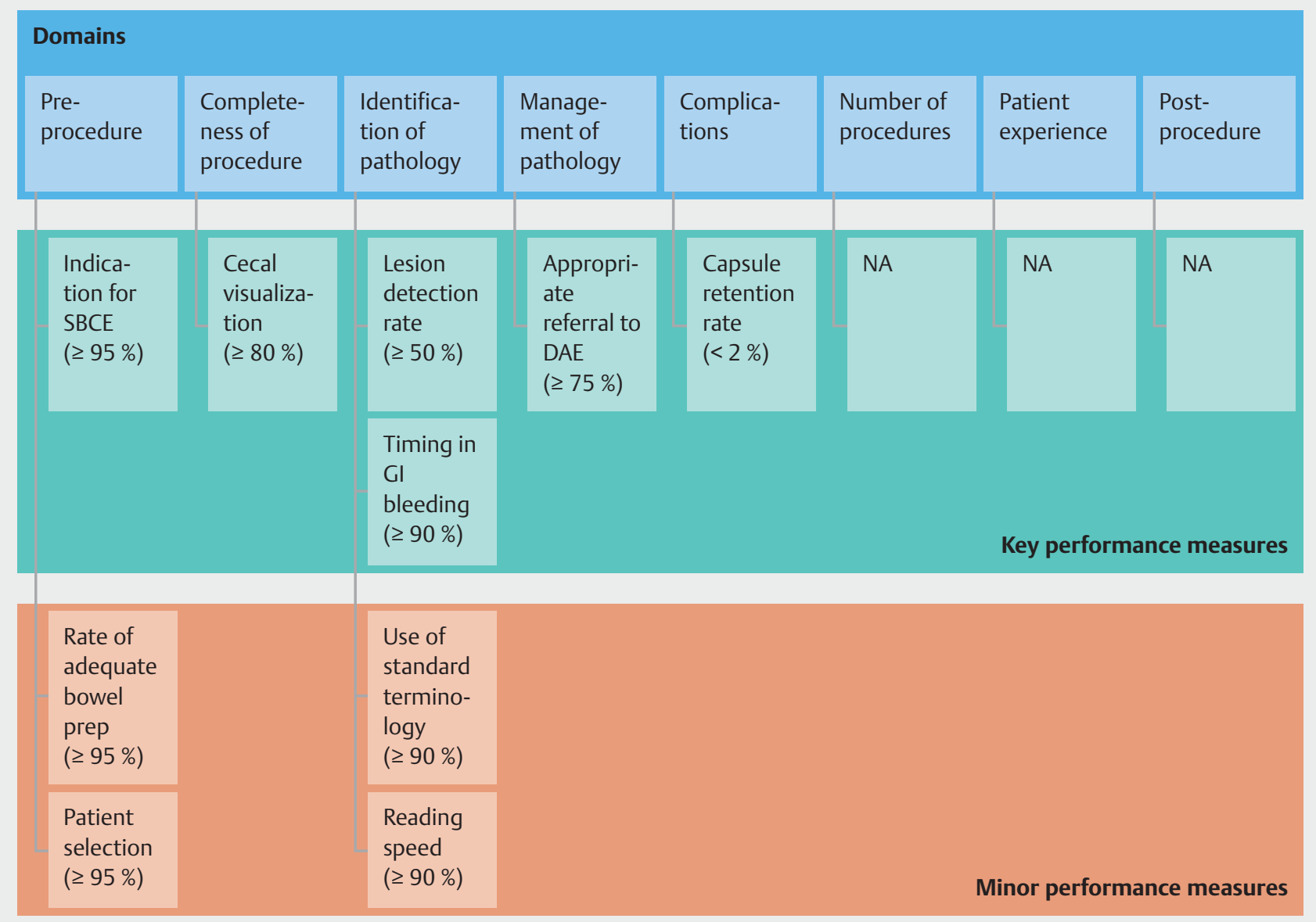

- Fig. 1 Key performance measures for small-bowel capsule endoscopy (SBCE). DAE, device-assisted enteroscopy; GI, gastrointestinal; NA, not applicable.

the working group, in total 25 PICOs were selected and retained as the basis of the literature searches. A detailed literature search was performed by a team of expert methodologists.

The evidence derived from the literature searches and input from the working group members were used to formulate a total of 23 clinical statements addressing 16 potential performance measures, grouped into eight quality domains. The PICOs and clinical statements were then adapted and/or excluded during the iterative rounds of voting and comments from the working group during the Delphi process. Over the course of three rounds of voting, consensus agreement was reached for 19 statements relating to 10 performance measures. The remaining clinical statements and performance measures did not reach agreement over the course of three rounds of voting; it was also impossible to define performance measures for two domains (i.e. number of procedures and post-procedure). Therefore, a final total of 10 performance measures (19 statements) attributed to six quality domains were accepted for these guidelines ( $\triangleright$ Fig. 2 ).

\section{Key and minor performance measures}

Although the overall evidence quality (as assessed using the GRADE criteria) for most of the performance measures for SBCE and DAE is low, this does not suggest that these performance measures are irrelevant. We used the highest mean voting scores to identify at least one key performance measure for each of the quality domains for each modality. When this process was not possible because performance measures had similar voting scores, the Quality Improvement Committee chair selected the key performance measure, and this was subsequently agreed by the whole working group.

The remaining performance measures were considered to be minor performance measures, but nevertheless all performance measures (identified by the rigorous process described above) were deemed to be valuable by the working group members. It was however agreed that, from a practical standpoint, it may be more acceptable to concentrate on the implementation of the key performance measures in the first instance. Once a culture of quality measurement (with the aim of optimizing practice, outcomes, and patient experience) is accepted and supporting software is available, the minor performance measures may then further aid the monitoring of 


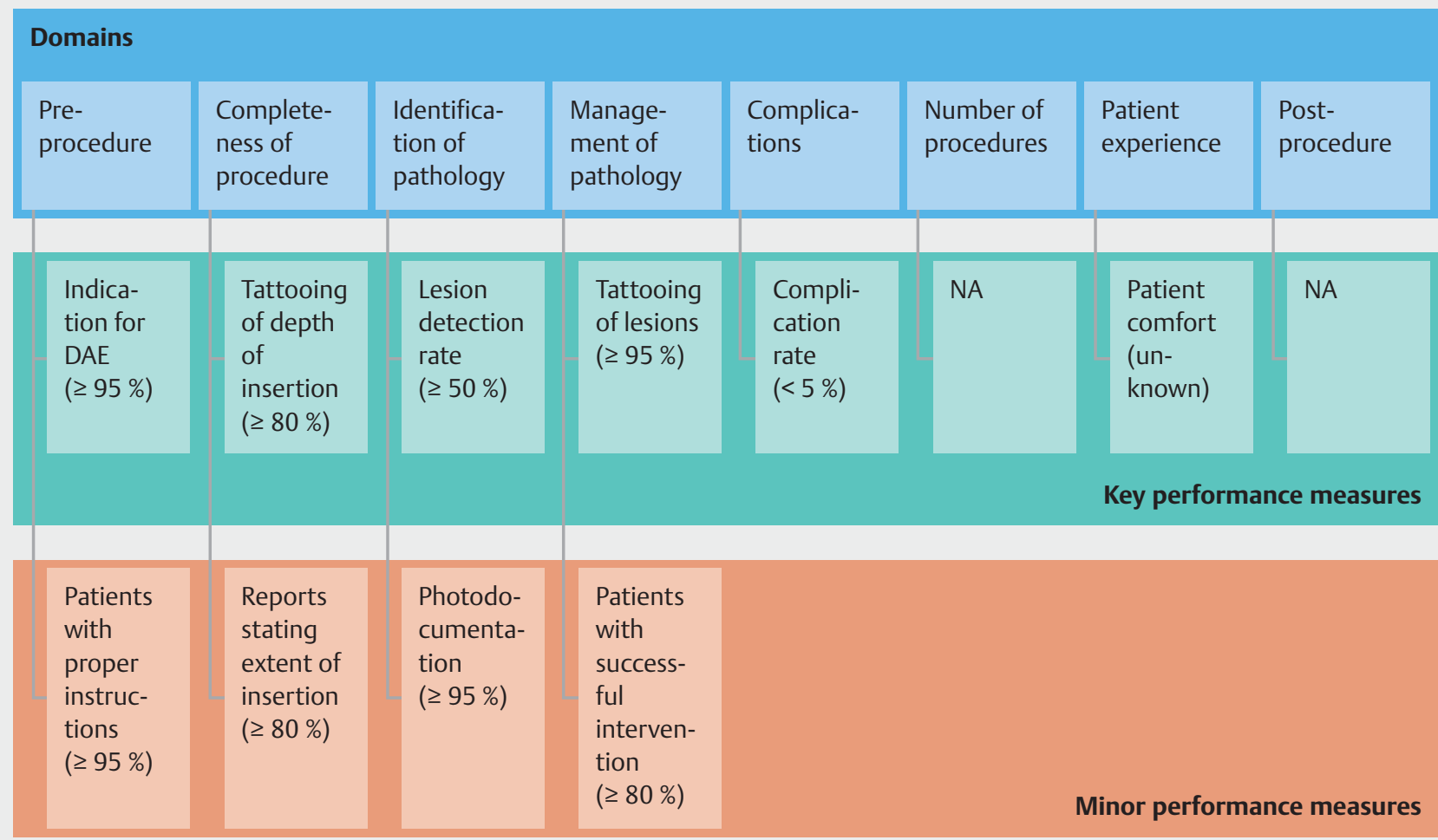

Fig. 2 Key performance measures for small-bowel device-assisted enteroscopy (DAE). NA, not applicable.

quality in small-bowel endoscopy. The use of appropriate endoscopy reporting systems is key to facilitate data retrieval on identified performance measures.

\section{Performance measures for small-bowel capsule endoscopy (SBCE) \\ 1 Domain: Pre-procedure}

\begin{tabular}{|l|l|}
\hline $\begin{array}{l}\text { Key per- } \\
\text { formance } \\
\text { measure }\end{array}$ & Indication for SBCE \\
\hline Description & $\begin{array}{l}\text { Percentage of patients undergoing SBCE in accordance } \\
\text { with published recommendations }\end{array}$ \\
\hline Domain & Pre-procedure \\
\hline Category & Process \\
\hline Rationale & $\begin{array}{l}\text { SBCEs performed for an appropriate indication are } \\
\text { associated with higher diagnostic yields for clinically } \\
\text { significant lesions }\end{array}$ \\
\hline Construct & $\begin{array}{l}\text { Denominator: All SBCEs performed } \\
\text { Numerator: SBCEs performed for an appropriate indi- } \\
\text { cation (according to the ESGE clinical guideline for } \\
\text { SBCE): obscure GI bleeding, iron deficiency anemia, } \\
\text { Crohn's disease (known or suspected), small-bowel } \\
\text { tumors, inherited polyposis syndromes, abnormal } \\
\text { radiological imaging, and subgroups of patients with } \\
\text { celiac disease (i. e. complicated and/or refractory celiac } \\
\text { disease) } \\
\text { Exclusions: None } \\
\text { Calculation: Proportion (\%) } \\
\text { Level of analysis: Service and individual level } \\
\text { Frequency: Yearly and/or for a sample of 100 SBCEs }\end{array}$ \\
\hline
\end{tabular}




\begin{tabular}{|c|c|}
\hline $\begin{array}{l}\text { Key per- } \\
\text { formance } \\
\text { measure }\end{array}$ & Indication for SBCE \\
\hline Standards & $\begin{array}{l}\text { Minimum standard: } \geq 95 \% \\
\text { Target standard: } \geq 95 \% \\
\text { If the minimum standard is not reached, analysis of the } \\
\text { appropriateness of the procedure should be performed } \\
\text { at a service level and for each capsule reader } \\
\text { After evaluation and adjustment, close monitoring } \\
\text { should be performed with a further audit within } 12 \\
\text { months and/or for a sample of } 100 \text { SBCEs }\end{array}$ \\
\hline $\begin{array}{l}\text { Consensus } \\
\text { agreement }\end{array}$ & $81.8 \%$ \\
\hline $\begin{array}{l}\text { PICO } \\
\text { number }\end{array}$ & 1.1 (see Supporting information, CE file) \\
\hline $\begin{array}{l}\text { Evidence } \\
\text { grading }\end{array}$ & Moderate quality evidence \\
\hline
\end{tabular}

The acceptance of this performance measure is based on the strength of agreement with the following statements:

- The indications for SBCE should be guided by published recommendations (e.g. ESGE guidelines). (Statement number 1.1) Agreement: $81.8 \%$

- The percentage of SBCE procedures performed by indication should be audited. (Statement number 1.1) Agreement: $81.8 \%$

- Studies performed for indications not included in a published standard list of appropriate indications approved by an internationally recognized endoscopy professional society should be documented and reviewed. (Statement number 1.1) Agreement: $81.8 \%$

Adherence to appropriate indications for SBCE may help to optimize the use of limited resources (considering the high costs relating to $S B C E$ ) and to protect patients from the potential harms of unnecessary procedures. SBCE performed for an appropriate indication is associated with significantly higher diagnostic yields for clinically relevant lesions, when compared with SBCE performed without an appropriate indication [2 -8].

The ESGE and American Society for Gastrointestinal Endoscopy (ASGE) have both produced guidelines with similar recommendations for the appropriate use of SBCE: obscure GI bleeding, iron deficiency anemia, Crohn's disease (known or suspected), small-bowel tumors, inherited polyposis syndromes, abnormal radiological imaging, and subgroups of patients with celiac disease (i.e. complicated and/or refractory celiac disease). Other indications such as abdominal pain, diarrhea, and malabsorption are associated with a low diagnostic yield and are therefore not considered to be appropriate indications for SBCE [9-11].

Studies performed for indications not approved by an internationally recognized endoscopy professional society should be documented, audited, and reviewed regularly.

The proposed minimum standard and target standard $(\geq 95 \%)$ for compliance with appropriate indications for SBCE were based on values reported in recent population-based studies from academic and non-academic centers. The use of appropriate endoscopy reporting systems with a drop-down menu for indication is key to facilitate data acquisition for this performance measure [12].

\begin{tabular}{|c|c|}
\hline $\begin{array}{l}\text { Minor per- } \\
\text { formance } \\
\text { measure }\end{array}$ & Rate of adequate bowel preparation \\
\hline Description & $\begin{array}{l}\text { Percentage of patients with an adequately prepared } \\
\text { small bowel }\end{array}$ \\
\hline Domain & Pre-procedure \\
\hline Category & Process \\
\hline Rationale & $\begin{array}{l}\text { Appropriate bowel preparation enhances small- } \\
\text { bowel mucosal visualization } \\
\text { Inadequate bowel preparation results in increased } \\
\text { costs and inconvenience as the examination may } \\
\text { need to be repeated or an alternative investigation } \\
\text { arranged }\end{array}$ \\
\hline Construct & $\begin{array}{l}\text { Denominator: Patients undergoing SBCE } \\
\text { Numerator: Patients in the denominator with an } \\
\text { adequate small-bowel cleansing level according to } \\
\text { any published, validated cleansing scale (i. e. Brotz } \\
\text { or Park scales) } \\
\text { Exclusions: Emergency SBCE, patients with active } \\
\text { bleeding, patients with previous small-bowel } \\
\text { resections } \\
\text { Calculation: Proportion (\%) } \\
\text { Level of analysis: Service and individual level } \\
\text { Frequency: Yearly and/or for a sample of } 100 \text { SBCEs }\end{array}$ \\
\hline Standards & $\begin{array}{l}\text { Minimum standard: } \geq 95 \% \\
\text { Target standard: } \geq 95 \% \\
\text { Bowel preparation quality should be included in the } \\
\text { report } \\
\text { If the minimum standard is not reached, analysis of } \\
\text { the factors influencing bowel preparation (informa- } \\
\text { tion given to patients, dietary restrictions, fasting, } \\
\text { cleansing agents used, timing) should be performed } \\
\text { on a service level } \\
\text { After evaluation and adjustment, close monitoring } \\
\text { should be performed with a further audit within } \\
12 \text { months }\end{array}$ \\
\hline $\begin{array}{l}\text { Consensus } \\
\text { agreement }\end{array}$ & $86.3 \%$ \\
\hline PICO number & 14.1 (see Supporting information, CE file) \\
\hline $\begin{array}{l}\text { Evidence } \\
\text { grading }\end{array}$ & Moderate quality evidence \\
\hline
\end{tabular}

The acceptance of this performance measure is based on the strength of agreement with the following statements:

- Visualization is higher in patients who received purgative agents. (Statement number 17.2) Agreement: $81.8 \%$

- The mucosal visualization obtained for SBCE should be adequate or good in greater than $95 \%$ of cases using accepted bowel preparation methods. (Statement number 17.1) Agreement: $90.9 \%$ 
Optimal bowel preparation for SBCE is controversial. As recommended by the ESGE clinical guideline, prior to SBCE, patients are requested to follow a modified diet and to ingest a purgative for better visualization. Suboptimal bowel preparation results in further costs and inconvenience because patients need to undergo either a repeat SBCE or an alternative investigation. Five systematic reviews [13-17] and 16 randomized controlled trials (RCTs) [18-32] were included for the analysis of the role of bowel preparation in patients undergoing SBCE and were considered potentially relevant. Four main interventions were examined: (a) purgatives, (b) antifoaming agents, (c) a combination of purgative and antifoaming agent, and (d) prokinetics.

Laxatives do not significantly improve diagnostic yield or completion rate in SBCE but do improve quality of small-bowel mucosal visualization. The use of laxatives may therefore be beneficial in patients likely to have subtle findings, although there is recent evidence to the contrary [33]. Bowel preparation is less well tolerated by patients and the addition of laxatives remains controversial.

RCTs demonstrate that antifoaming agents improve the quality of mucosal visualization $[10,14]$ and meta-analyses have concluded that simethicone has a positive impact on the quality of preparation as it significantly decreases the presence of luminal bubbles/foam [14, 17, 18, 24, 26, 34-55]. The combination of purgatives and antifoaming agents does not increase diagnostic yield; however, it may play a role in improving the quality of small-bowel mucosal visualization.

Prokinetics do not improve completion rate nor the diagnostic yield of SBCE and their routine administration is not recommended. It is to be noted, however, that there is considerable heterogeneity in methodology and definitions used in different studies $[14,15]$.

A regimen of preparation, as well as the most appropriate timing for small-bowel preparation, has not been standardized. Unlike colonoscopy, there is no standardized, validated scale available for the evaluation of cleansing achieved for SBCE and such a tool should be developed for standardized scoring and recording of SBCE findings. Small-bowel luminal contents, such as food residue, blood, bile, and bubbles/foam, which hinder adequate small-bowel mucosal visualization, are usually subjectively evaluated. Subjectivity is also currently applied to the overall assessment of small-bowel preparation quality.

Several cleansing scales for capsule endoscopy have been proposed, some of which have already been validated [56]. Among the others, the Brotz and Park scales have been validated and are relatively commonly adopted $[57,58]$.

In a prospective, randomized, single-center validation study, Brotz et al. [58] assessed the adequacy of small-bowel cleansing for capsule endoscopy according to three scales: quantitative index, qualitative evaluation, and overall adequacy assessment. The authors showed a strong and highly significant association between the quantitative index, qualitative evaluation, and overall adequacy assessment. The authors also concluded that the adequacy of small-bowel cleansing should be incorporated into the standard capsule endoscopy report as an important quality measure.
Similarly, Park et al. [57] developed a small-bowel cleansing score assessing two visual parameters: proportion of visualized mucosa and degree of obscuration. The first parameter was the proportion of visualized mucosa. This was scored using a 4-step scale ranging from 0 to 3 : score $3,>75 \%$; score $2,50 \%-75 \%$; score $1,25 \%-50 \%$; score $0,<25 \%$. The second parameter was the degree of obscuration by bubbles, debris, and bile etc. This was scored using a 4-step scale ranging from 0 to 3: score 3, no $(<5 \%)$ obscuration; score 2 , mild $(5 \%-25 \%)$ obscuration; score 1 , moderate $(25 \%-50 \%)$ obscuration; score 0 , severe $(>50 \%)$ obscuration. For the evaluation, representative frames from small-bowel images were serially selected and scored at 5minute intervals. The reliability of the grading system was evaluated by assessing the interobserver, intrapatient, and intraobserver agreement, which resulted in excellent agreement.

The development/identification of a single, universally accepted, validated scale, as well as the development of software for assessment of the quality of small-bowel preparation, would allow standardized evaluation and monitoring of this performance measure. In the absence of these data, individual clinicians are expected to make a judgement as to whether or not any given study is adequate, based on any validated scale that they are confident in using and familiar with $[59,60]$. There are insufficient data to set the minimum and target standards reliably, but the proposed value for the rate of adequate bowel preparation of $\geq 95 \%$ was deemed to be a reasonable objective.

\begin{tabular}{|c|c|}
\hline $\begin{array}{l}\text { Minor per- } \\
\text { formance } \\
\text { measure }\end{array}$ & Patient selection \\
\hline Description & $\begin{array}{l}\text { Patients at high risk of capsule retention should be } \\
\text { identified before undergoing SBCE }\end{array}$ \\
\hline Domain & Pre-procedure \\
\hline Category & Process \\
\hline Rationale & $\begin{array}{l}\text { Patients at high risk of capsule retention should be } \\
\text { identified and a patency capsule should be offered }\end{array}$ \\
\hline Construct & $\begin{array}{l}\text { Denominator: SBCE performed in high risk patients } \\
\text { (i. e. known Crohn's disease, symptoms of obstruction, } \\
\text { long-term NSAID use, abdominopelvic radiation) } \\
\text { Numerator: Number of patency capsules offered to } \\
\text { high risk patients } \\
\text { Exclusions: None } \\
\text { Calculation: Proportion (\%) } \\
\text { Level of analysis: Service and individual level } \\
\text { Frequency: Yearly }\end{array}$ \\
\hline
\end{tabular}




\begin{tabular}{|c|c|}
\hline $\begin{array}{l}\text { Minor per- } \\
\text { formance } \\
\text { measure }\end{array}$ & Patient selection \\
\hline Standards & $\begin{array}{l}\text { Minimum standard: } \geq 95 \% \\
\text { Target standard: } \geq 95 \% \\
\text { The report should include an explicit description of the } \\
\text { risk of retention in high risk patients. Patients at high } \\
\text { risk of capsule retention should be offered a patency } \\
\text { capsule to reduce the incidence of retention } \\
\text { If the minimum standard is not reached, analysis of } \\
\text { the factors influencing proper patient selection } \\
\text { should be performed on a service level and for each } \\
\text { capsule endoscopist } \\
\text { After evaluation and adjustment, close monitoring } \\
\text { should be performed with a further audit within } \\
12 \text { months and/or for a sample of } 100 \mathrm{SBCEs}\end{array}$ \\
\hline $\begin{array}{l}\text { Consensus } \\
\text { agreement }\end{array}$ & $90.9 \%$ \\
\hline $\begin{array}{l}\text { PICO num- } \\
\text { bers }\end{array}$ & 3.1 and 8.1 (see Supporting information, CE file) \\
\hline $\begin{array}{l}\text { Evidence } \\
\text { grading }\end{array}$ & Moderate quality evidence \\
\hline
\end{tabular}

The acceptance of this performance measure is based on the strength of agreement with the following statements:

- Certain groups of patients undergoing SBCE have a greater risk of capsule retention. (Statement number 7.1) Agreement: $90.9 \%$

- The use of a patency capsule can reduce the incidence of capsule retention in patients at higher risk. (Statement number 11.1) Agreement: 90.9\%

It is well established that certain underlying conditions predispose to capsule retention. A recently published meta-analysis showed that the capsule retention rate was $2.1 \%$ for patients with suspected small-bowel bleeding $(95 \% \mathrm{Cl} 1.5 \%-2.8 \%)$ and $3.6 \%(95 \% \mathrm{Cl} 1.7 \%-8.6 \%)$ for suspected inflammatory bowel disease (IBD). For established IBD, the capsule retention rate reached $8.2 \%(95 \% \mathrm{Cl} 6.0 \%-11.0 \%)$ [61].

The overall capsule retention rate is low and it is related to clinical indication. The presence of symptoms such as abdominal pain, abdominal distension, and nausea/vomiting are associated with a significantly higher rate of capsule retention. Furthermore, previous small-bowel resection, abdominal/pelvic radiation therapy, and chronic use of high dose nonsteroidal anti-inflammatory drugs (NSAIDs) have all been shown to increase the risk of capsule retention [2,61] Therefore, a careful assessment of past medical history is mandatory in order to select patients who require a specific work-up aimed at preventing capsule retention.

The use of a patency capsule can reduce the incidence of capsule retention in high risk patients. The use of a patency capsule has been shown to accurately identify the presence of stenosis as well as, or better than, standard radiological techniques and is at least comparable to dedicated cross-sectional imaging modalities. Although unable to provide direct visual in- formation regarding the presence and location of strictures, masses, or other causes of luminal narrowing of the small bowel, a successful patency capsule examination minimizes the risk of retention in high risk patients and allows for a safer SBCE procedure.

This performance measure can and should be implemented at both a service and individual endoscopist level. Variations from the expected capsule retention rates suggest suboptimal patient selection and procedure quality. There are insufficient data to set the minimum and target standards reliably, but the proposed values for proper selection of patients of $\geq 95 \%$, respectively, were deemed appropriate to ensure safer SBCE.

\section{Domain: Completeness of procedure}

\begin{tabular}{|c|c|}
\hline $\begin{array}{l}\text { Key per- } \\
\text { formance } \\
\text { measure }\end{array}$ & Complete cecal or stomal visualization \\
\hline Description & Percentage of SBCEs reaching the cecum or stoma \\
\hline Domain & Completeness of procedure \\
\hline Category & Process \\
\hline Rationale & $\begin{array}{l}\text { Complete small-bowel visualization is a prerequisite } \\
\text { for an adequate inspection of the mucosa in search of } \\
\text { lesions }\end{array}$ \\
\hline Construct & $\begin{array}{l}\text { Denominator: All SBCEs performed } \\
\text { Numerator: Procedures that report reaching the } \\
\text { cecum/colon or stoma bag (in patients who have had } \\
\text { ileocolonic resection or other relevant surgery) } \\
\text { Exclusions: None } \\
\text { Calculation: Proportion (\%) } \\
\text { Level of analysis: Service and individual level } \\
\text { Frequency: Yearly and/or for a sample of } 100 \text { SBCEs }\end{array}$ \\
\hline Standards & $\begin{array}{l}\text { Minimum standard: } \geq 80 \% \\
\text { Target standard: } \geq 95 \% \\
\text { Complete small-bowel visualization should be } \\
\text { documented in a written report, including photo- } \\
\text { documentation } \\
\text { If the minimum standard is not reached, analysis of } \\
\text { the factors influencing completion rate (selection of } \\
\text { patients, cleansing agents used, timing) should be } \\
\text { performed on a service level and for each individual } \\
\text { capsule endoscopist } \\
\text { After evaluation and adjustment, close monitoring } \\
\text { should be performed with a further audit within } \\
12 \text { months and/or for a sample of } 100 \text { SBCEs }\end{array}$ \\
\hline $\begin{array}{l}\text { Consensus } \\
\text { agreement }\end{array}$ & $100 \%$ \\
\hline $\begin{array}{l}\text { PICO } \\
\text { numbers }\end{array}$ & 1.4 and 2.1 (see Supporting information, CE file) \\
\hline $\begin{array}{l}\text { Evidence } \\
\text { grading }\end{array}$ & Low quality evidence \\
\hline
\end{tabular}


The acceptance of this performance measure is based on the strength of agreement with the following statements:

- The incomplete study rate (failure to reach the colon or stoma bag) should be less than $20 \%$. (Statement number 4.1 ) Agreement: $100 \%$

- In all cases of an incomplete study, the patient should be asked to confirm excretion. If excretion is not confirmed after 15 days, an abdominal radiograph should be obtained. (Statement number 5.1) Agreement: 100\%

Visualization of the colon or a stoma is a prerequisite for confirming complete visualization of the small bowel. Incomplete SBCE results in further costs owing to the repetition of SBCE and/or an alternative investigation. Patients undergoing SBCE should be instructed to check for excretion of the capsule. In cases where the capsule did not reach the colon or the stoma within the duration of the recording and the patient does not confirm excretion within 2 weeks of ingestion, an abdominal radiograph should be obtained to rule out capsule retention (unless contraindicated). A completion rate $<80 \%$ may be associated with a higher risk of missing significant pathology; nevertheless, the true magnitude of this risk is unclear.

For grading this performance measure, 39 studies $[2,4,62-$ 98] with 18035 procedures were analyzed. All were retrospective or prospective analyses of registries of single- or multiplecenter experiences. The percentage of complete examinations was reported in 23 studies. The results were heterogenous, ranging from $64 \%$ to $96 \%$, with a median of $80 \%$ complete SBCEs.

\section{Domain: Identification of pathology}

\begin{tabular}{|c|c|}
\hline $\begin{array}{l}\text { Key per- } \\
\text { formance } \\
\text { measure }\end{array}$ & Lesion detection rate \\
\hline Description & Diagnostic yield of SBCE per indication \\
\hline Domain & Identification of pathology \\
\hline Category & Process \\
\hline Rationale & $\begin{array}{l}\text { Lesion detection reflects adequate inspection of the } \\
\text { small-bowel mucosa } \\
\text { Lesion detection rates by indication predict quality in } \\
\text { SBCE }\end{array}$ \\
\hline Construct & $\begin{array}{l}\text { Denominator: All SBCEs performed } \\
\text { Numerator: SBCEs which provide a diagnosis or a } \\
\text { finding considered significant and related to the } \\
\text { indication, including: } \\
\text { - P2 and P1 lesions according to the Saurin classifica- } \\
\text { tion for intestinal bleeding } \\
\text { - ulceration, erosions, or strictures in the context of } \\
\text { suspected/established Crohn's disease } \\
\text { - small-bowel tumors } \\
\text { - small-bowel polyps } \\
\text { Exclusions: None } \\
\text { Calculation: Proportion (\%) } \\
\text { Level of analysis: Service level } \\
\text { Frequency: Yearly and/or for a sample of } 100 \text { SBCEs }\end{array}$ \\
\hline
\end{tabular}

\begin{tabular}{|c|c|}
\hline $\begin{array}{l}\text { Key per- } \\
\text { formance } \\
\text { measure }\end{array}$ & Lesion detection rate \\
\hline Standards & $\begin{array}{l}\text { Minimum standard: } \geq 50 \% \\
\text { Target standard: } \geq 50 \% \\
\text { A written description and photodocumentation of } \\
\text { significant lesions should be included in the report } \\
\text { Overall diagnostic yields per indication should be } \\
\text { audited. Variations from expected rates raise the } \\
\text { possibility of suboptimal patient selection, procedure } \\
\text { quality, and/or reading, and reporting } \\
\text { After evaluation and adjustment, close monitoring } \\
\text { should be performed with a further audit }\end{array}$ \\
\hline $\begin{array}{l}\text { Consensus } \\
\text { agreement }\end{array}$ & $100 \%$ \\
\hline $\begin{array}{l}\text { PICO num- } \\
\text { ber }\end{array}$ & 1.2 (see Supporting information, CE file) \\
\hline $\begin{array}{l}\text { Evidence } \\
\text { grading }\end{array}$ & Low quality evidence \\
\hline
\end{tabular}

The acceptance of this performance measure is based on the strength of agreement with the following statements:

- The overall diagnostic yield of SBCE depends on the referral population, and adherence to ESGE guidelines. (Statement number 2.1) Agreement: $100 \%$

- Currently available data do not support a single optimal diagnostic yield per indication and as such regular audit is required to ensure adherence with ESGE guidelines on the indications for SBCE and $>95 \%$ compliance achieved. (Statement number 2.1) Agreement: $100 \%$

Available studies of SBCE diagnostic yield are mainly reports of clinical experience without clearly defined indications for the procedure. These indications include: suspected small-bowel bleeding (overt and/or occult); suspected or established Crohn's disease, malabsorption, diarrhea, abdominal pain, polyp surveillance, suspected tumors, and abnormal radiological imaging. Therefore, the patient populations studied, and diagnostic yields showed wide variation. Diagnostic yield for mixed indications varied between $27 \%$ and $77.3 \%$ [2,63-64, $66,72,74,76,79-82,86,88-92,95,97,99-100]$; for suspected Gl bleeding, between $31 \%$ and $68 \%$, [4, 62, 65, 67, 70-71, 77 , $85,87,93-94,98,101]$; for suspected Crohn's disease, between $6 \%$ and $38 \%$ (although definition of Crohn's disease also varied) $[68,73,82,93]$; with a $39 \%$ yield of active disease in patients with established Crohn's disease [82].

The working group agreed that a diagnostic yield of at least $50 \%$ in all patients having SBCE (for any indication) was a reasonable aim. It was acknowledged that there may be situations in which there was uncertainty in distinguishing pathology from normal variants and bowel content, and in terms of whether the lesions identified were relevant to the indication of the procedure and were a "true diagnosis." Therefore, it was agreed that there should be a minimum requirement for a writ- 
ten description and photodocumentation of any lesion considered significant.

For patients with suspected GI bleeding, the Saurin classification is advisable for the evaluation of the relevance of the lesions [102]. According to the Saurin classification, lesions detected at capsule endoscopy are classified as P0, P1, and P2. P0 lesions are those having no potential for bleeding, including visible submucosal veins, diverticula without the presence of blood, or nodules without mucosal break. P1 lesions are those regarded as having uncertain hemorrhagic potential, such as red spots on the intestinal mucosa, or small or isolated erosions. P2 lesions are those considered to have a high potential for bleeding, such as typical angiomas, large ulcerations, tumors, or varices. For indications other than GI bleeding, a universally accepted classification is lacking; however, the presence on SBCE of ulceration, erosions, and/or strictures in the context of a patient with suspected/established Crohn's disease, along with the findings of small-bowel tumors and smallbowel polyps, are considered significant findings.

The working group recognized that the overall diagnostic yield was likely to be affected by the referral practice of individual units; however, diagnostic yield per indication should be audited, with any major variations from that reported in the published experience subjected to further scrutiny and in-depth analysis.

\begin{tabular}{|c|c|}
\hline $\begin{array}{l}\text { Key per- } \\
\text { formance } \\
\text { measure }\end{array}$ & Timing of SBCE for overt bleeding \\
\hline Description & Timing of SBCE in small-bowel bleeding \\
\hline Domain & Identification of pathology \\
\hline Category & Process \\
\hline Rationale & $\begin{array}{l}\text { In patients with overt small-bowel bleeding, timing of } \\
\text { the performance of SBCE impacts the diagnostic yield. } \\
\text { Earlier performance of SBCE achieves a higher diagnos- } \\
\text { tic yield in this subgroup }\end{array}$ \\
\hline Construct & $\begin{array}{l}\text { Denominator: Proportion of SBCEs performed in the } \\
\text { context of overt bleeding } \\
\text { Numerator: SBCEs performed within } 14 \text { days of overt } \\
\text { bleeding episode } \\
\text { Exclusions: None } \\
\text { Calculation: Proportion (\%) } \\
\text { Level of analysis: Service level } \\
\text { Frequency: Yearly and/or for a sample of } 100 \text { SBCEs }\end{array}$ \\
\hline Standards & $\begin{array}{l}\text { Minimum standard: } \geq 90 \% \\
\text { Target standard: } \geq 90 \% \\
\text { Cutoff for timing varies among studies; however, } \\
\text { earlier performance of SBCE achieves a higher diagnos- } \\
\text { tic yield for patients with overt small-bowel bleeding. } \\
\text { Interval from last bleeding episode should be docu- } \\
\text { mented in a written report } \\
\text { The timing of capsule endoscopy in patients with overt } \\
\text { small-bowel bleeding should be audited. Variations } \\
\text { from expected rates may suggest suboptimal timing } \\
\text { After evaluation and adjustment, close monitoring } \\
\text { should be performed with a further audit }\end{array}$ \\
\hline
\end{tabular}

\begin{tabular}{|l|l|}
\hline $\begin{array}{l}\text { Key per- } \\
\text { formance } \\
\text { measure }\end{array}$ & Timing of SBCE for overt bleeding \\
\hline $\begin{array}{l}\text { Consensus } \\
\text { agreement }\end{array}$ & $100 \%$ \\
\hline $\begin{array}{l}\text { PICO } \\
\text { number }\end{array}$ & 13.1 (see Supporting information, CE file) \\
\hline $\begin{array}{l}\text { Evidence } \\
\text { grading }\end{array}$ & Moderate quality evidence \\
\hline
\end{tabular}

The acceptance of this performance measure is based on the strength of agreement with the following statement:

- Earlier timing of SBCE achieves a higher diagnostic yield in patients with overt small-bowel bleeding. (Statement number 16.1) Agreement: $100 \%$

In the context of overt small-bowel bleeding, performing SBCE closer to an episode of bleeding appears to correlate with an increased diagnostic yield [3-8]. Although the optimal timing for the performance of SBCE in this setting is unknown, in line with ESGE guidance [9], the working group adopted the cutoff point of 14 days from the episode of bleeding as a measure of quality for audit.

As a minimum requirement, the interval from the last bleeding episode should be documented in the written report and the timing of SBCE performance in patients with overt smallbowel bleeding should be audited. Variations from expected rates may suggest suboptimal timing of procedures.

\begin{tabular}{|c|c|}
\hline $\begin{array}{l}\text { Minor } \\
\text { perform- } \\
\text { ance } \\
\text { measure }\end{array}$ & Use of standard terminology \\
\hline $\begin{array}{l}\text { Descrip- } \\
\text { tion }\end{array}$ & Reporting of SBCE procedures \\
\hline Domain & Identification of pathology \\
\hline Category & Process \\
\hline Rationale & Uniformity in communication \\
\hline Construct & $\begin{array}{l}\text { Denominator: SBCE reports produced per unit } \\
\text { Numerator: SBCE reports that include patient demo- } \\
\text { graphics, details of capsule used, indication, examina- } \\
\text { tion characteristics, findings, recommendations, and } \\
\text { complications, a detailed breakdown of descriptive } \\
\text { methodology describing lumen, content, mucosal } \\
\text { appearances, and any lesions identified } \\
\text { Exclusions: None } \\
\text { Calculation: Proportion (\%) } \\
\text { Level of analysis: Service level } \\
\text { Frequency: Yearly and/or for a sample of } 100 \text { SBCEs }\end{array}$ \\
\hline
\end{tabular}




\begin{tabular}{|c|c|}
\hline $\begin{array}{l}\text { Minor } \\
\text { perform- } \\
\text { ance } \\
\text { measure }\end{array}$ & Use of standard terminology \\
\hline Standards & $\begin{array}{l}\text { Minimum standard: } \geq 90 \% \\
\text { Target standard: } \geq 90 \% \\
\text { Description of findings using an appropriate and stand- } \\
\text { ardized terminology is fundamental. If the threshold is } \\
\text { not reached at a service level, the service should verify } \\
\text { whether technical support is needed to achieve the } \\
\text { standard } \\
\text { If the threshold is not reached for an individual endos- } \\
\text { copist, feedback should be provided followed by close } \\
\text { monitoring for } 12 \text { months in order to assess the per- } \\
\text { formance of the individual endoscopist } \\
\text { After evaluation and adjustment, close monitoring } \\
\text { should be performed with a further audit }\end{array}$ \\
\hline $\begin{array}{l}\text { Consensus } \\
\text { agreement }\end{array}$ & $100 \%$ \\
\hline $\begin{array}{l}\text { PICO num- } \\
\text { ber }\end{array}$ & 12.1 (see Supporting information, CE file) \\
\hline $\begin{array}{l}\text { Evidence } \\
\text { grading }\end{array}$ & Very low quality of evidence \\
\hline
\end{tabular}

The acceptance of this performance measure is based on the agreement with the following statement:

- Structured and standardized reporting improves the consistency of image interpretation, the description of findings, and patient management. It also facilitates audit and collation of study databases, but does not improve diagnostic yield. (Statement number 15.1) Agreement: 100\%

No studies of the effect of using a standardized terminology on image interpretation or diagnostic yield were identified. However, the minimal standard terminology for documentation in flexible endoscopy was devised in recognition of the value that this brings to the retrieval of information from databases for the purpose of audit, research, and the facilitation of education and training [82]. A similar process was followed in the creation of the capsule endoscopy structured terminology (CEST), in which the standard considers a report in two components: structure and content [103].

The CEST standardizes the documentation of: patient demographics, details of capsule used, indication, examination characteristics, findings, recommendations, and complications. It includes a detailed breakdown of descriptive methodology in terms of lumen, content, mucosal appearances, and any lesions identified. Validation was defined as the CEST inclusion for $\geq 90 \%$ of all descriptors used in any one section of a historical cohort of reports [104].

Two studies suggest a moderate degree of agreement in reporting using CEST, especially amongst experts $[105,106]$.

\begin{tabular}{|c|c|}
\hline $\begin{array}{l}\text { Minor per- } \\
\text { formance } \\
\text { measure }\end{array}$ & Reading speed of SBCE \\
\hline Description & Reading speed \\
\hline Domain & Identification of pathology \\
\hline Category & Process \\
\hline Rationale & $\begin{array}{l}\text { SBCE reading reflects adequate inspection of the } \\
\text { small-bowel mucosa and predicts quality }\end{array}$ \\
\hline Construct & $\begin{array}{l}\text { Denominator: SBCEs performed in a unit } \\
\text { Numerator: SBCE where reading speed is up to } \\
10 \text { frames per second in single view or } 20 \text { frames per } \\
\text { second in dual-/multiview } \\
\text { Exclusions: None } \\
\text { Calculation: Proportion (\%) } \\
\text { Level of analysis: Service level } \\
\text { Frequency: Yearly and/or for a sample of } 100 \text { SBCEs }\end{array}$ \\
\hline Standards & $\begin{array}{l}\text { Minimum standard: } \geq 90 \% \\
\text { Target standard: } \geq 95 \% \\
\text { Reading speed should not compromise diagnostic } \\
\text { yields. In case of compromised diagnostic yields, read- } \\
\text { ing speed should be audited. Variations from expected } \\
\text { rates of diagnostic yield might suggest a suboptimal } \\
\text { reading speed } \\
\text { After evaluation and adjustment, close monitoring } \\
\text { should be performed with a further audit }\end{array}$ \\
\hline $\begin{array}{l}\text { Consensus } \\
\text { agreement }\end{array}$ & $81 \%$ \\
\hline $\begin{array}{l}\text { PICO } \\
\text { numbers }\end{array}$ & 11.1 and 11.3 (see Supporting information, CE file) \\
\hline $\begin{array}{l}\text { Evidence } \\
\text { grading }\end{array}$ & Moderate quality evidence \\
\hline
\end{tabular}

The acceptance of this performance measure is based on the strength of agreement with the following statements:

- For all indications and in all cases, reading speed should be in accordance with the ESGE technical review. (Statement number 14.6) Agreement: $80 \%$

- Reading speed should be appropriate such that lesion detection is not compromised, and sufficient diagnostic yields are achieved on regular audit, when patient selection and indication are in line with ESGE guidance. (Statement number 14.6) Agreement: $80 \%$

- Reading time is significantly shorter with software that eliminates repeated identical images than conventional viewing. (Statement number 14.1) Agreement: $81.8 \%$

In line with the ESGE technical review [10], the small-bowel working group recommends that recordings should be read at a maximum speed of 10 frames per second (single view); if double-/multiple-view modes are used, a maximum reading speed of 20 frames per second is advised. Also, in line with the ESGE technical review, the working group supports the recommendation that particular vigilance must be paid (and the reading 
frame rate further slowed) within the proximal small bowel, where the risk of missing lesions appears to be higher $[10,107]$.

The small-bowel working group also supports the ESGE technical recommendations [10] relating to automated software algorithms designed to shorten reading time, in that these may be used to scan the small bowel for diffuse lesions (associated with Crohn's disease for example), but should not be relied on to detect an isolated lesion. Moreover, in accordance with the ESGE technical review, the use of virtual chromoendoscopy and "blue mode" imaging is not recommended for routine use, because this has not been shown to improve diagnostic yield or enhance detection or characterization of small-bowel mucosal pathology [10].

\section{Domain: Management of pathology}

\begin{tabular}{|c|c|}
\hline $\begin{array}{l}\text { Key per- } \\
\text { formance } \\
\text { measure }\end{array}$ & Appropriate referral for DAE \\
\hline $\begin{array}{l}\text { Descrip- } \\
\text { tion }\end{array}$ & Rate of enteroscopy after previous SBCE \\
\hline Domain & Management of pathology \\
\hline Category & Process \\
\hline Rationale & $\begin{array}{l}\text { DAE is efficacious (diagnostic and therapeutic impact) } \\
\text { when performed after SBCE. There are improved lesion } \\
\text { detection rates/reduced miss rates when enteroscopy is } \\
\text { performed after SBCE }\end{array}$ \\
\hline Construct & $\begin{array}{l}\text { Denominator: Positive SBCEs performed in a unit } \\
\text { Numerator: Post-SBCE referral for DAE in accordance } \\
\text { with the ESGE technical review } \\
\text { DAE following SBCE is indicated in patients with: } \\
\text { - significant findings at capsule endoscopy (P1 and P2 } \\
\text { lesions according to the Saurin classification for GI } \\
\text { bleeding) } \\
\text { - a suspicion of Crohn's disease on SBCE (for biopsy) } \\
\text { - suspicion of a small-bowel tumor (for biopsy and/or } \\
\text { tattooing) } \\
\text { - when a submucosal mass is detected by SBCE } \\
\text { - inherited polyposis syndromes when polypectomy is } \\
\text { indicated } \\
\text { - nonresponsive or refractory celiac disease (for biopsy) } \\
\text { Exclusions: None } \\
\text { Calculation: Proportion (\%) } \\
\text { Level of analysis: Service level } \\
\text { Frequency: Yearly and/or for a sample of } 100 \text { SBCEs }\end{array}$ \\
\hline Standards & $\begin{array}{l}\text { Minimum standard: } \geq 75 \% \\
\text { Target standard: } \geq 90 \% \\
\text { If the minimum standard is not reached, the pre- } \\
\text { procedure assessment for enteroscopy should be } \\
\text { reviewed and revised on a service level } \\
\text { After evaluation and adjustment, close monitoring } \\
\text { should be performed with a further audit within } 6 \text { months }\end{array}$ \\
\hline $\begin{array}{l}\text { Consen- } \\
\text { sus agree- } \\
\text { ment }\end{array}$ & $81.8 \%$ \\
\hline $\begin{array}{l}\text { PICO } \\
\text { number }\end{array}$ & 7.1 (see Supporting information, CE file) \\
\hline $\begin{array}{l}\text { Evidence } \\
\text { grading }\end{array}$ & Low quality evidence \\
\hline
\end{tabular}

The acceptance of this performance measure is based on the strength of agreement with the following statement:

- The use of SBCE prior to DAE improves the diagnostic yield. Prior SBCE is associated with an increased diagnostic and therapeutic yield during DAE. (Statement number 10.1) Agreement: $81.8 \%$

Pathological findings at SBCE may warrant further investigation (and possible endotherapy) by DAE and, in this context, SBCEreported findings should serve as a guide. Clear description of any lesion identified and its location (as described in the ESGE technical review [10]) will help the enteroscopist to select the most appropriate route of approach (i.e. antegrade vs. retrograde) and any potential endotherapy that may be applied.

\section{Domain: Complications}

\begin{tabular}{|c|c|}
\hline $\begin{array}{l}\text { Key per- } \\
\text { formance } \\
\text { measure }\end{array}$ & Capsule retention rate \\
\hline Description & $\begin{array}{l}\text { Percentage of patients in which retention occurred } \\
\text { after SBCE }\end{array}$ \\
\hline Domain & Complications \\
\hline Category & Outcome / Process \\
\hline Rationale & $\begin{array}{l}\text { Monitoring of the incidence of capsule retention is im- } \\
\text { portant to assess the overall safety of the procedure, } \\
\text { identify those patients at greater risk of complications, } \\
\text { identify possible targets for improvement, and allow } \\
\text { accurate informed consent of patients }\end{array}$ \\
\hline Construct & $\begin{array}{l}\text { Denominator: All SBCEs performed } \\
\text { Numerator: Procedures in which the capsule was } \\
\text { retained for > } 15 \text { days and/or required additional } \\
\text { intervention } \\
\text { Exclusions: None } \\
\text { Calculation: Proportion (\%) } \\
\text { Level of analysis: Service and individual level } \\
\text { Frequency: Yearly and/or for a sample of } 100 \text { SBCEs }\end{array}$ \\
\hline Standards & $\begin{array}{l}\text { Minimum standard: }<2 \% \\
\text { Target standard: }<2 \% \\
\text { Incomplete SBCE should be documented in a written } \\
\text { report, as well as with photodocumentation of relevant } \\
\text { lesions. If the minimum standard is not achieved, } \\
\text { pre-procedure assessment for SBCE should be } \\
\text { reviewed and revised on a service level and for } \\
\text { individual endoscopists } \\
\text { After evaluation and adjustment, close monitoring } \\
\text { should be performed with a further audit within } \\
12 \text { months }\end{array}$ \\
\hline $\begin{array}{l}\text { Consensus } \\
\text { agreement }\end{array}$ & $80 \%$ \\
\hline $\begin{array}{l}\mathrm{PICO} \\
\text { number }\end{array}$ & 3.2 (see Supporting information, CE file) \\
\hline $\begin{array}{l}\text { Evidence } \\
\text { grading }\end{array}$ & Moderate quality evidence \\
\hline
\end{tabular}


The acceptance of this performance measure is based on the strength of agreement with the following statement:

- Retention rates should be audited in all cases against known rates. Variations from expected rates suggest suboptimal patient selection and procedure quality. (Statement number 7.2) Agreement: $80 \%$

SBCE is a generally safe, non-invasive modality to visualize the small-bowel mucosa and is now the recommended first-line small-bowel investigation for several indications. However, adverse events may occur in up to $2 \%$ of cases overall; these include: capsule retention, aspiration, and capsule-induced bleeding or perforation [113]. A knowledge of SBCE-related complications improves patient care and safety by ensuring that only patients for whom the procedure is appropriate are selected. This knowledge, and awareness of it, is critical for appropriate informed consent prior to SBCE and facilitates early identification of adverse events and their appropriate management.

Currently there is insufficient evidence to reach a consensus on an acceptable overall complication rate for SBCE or to define individual target standards for any complication, other than for capsule retention. In light of this, regular audit of SBCE-related complications is advised to enhance the SBCE user knowledgebase and to identify individual as well as unit variance over time.

Capsule retention is defined as a capsule remaining in the Gl tract for 15 days (or less if medical, endoscopic, or surgical intervention was deemed necessary). Although uncommon, capsule retention is a serious potential complication of SBCE and warrants assessment as a key performance measure for all centers and individual endoscopists. Appropriate patient selection and the use of a patency capsule, where indicated, all play an important role in avoiding retention and can influence retention rates, which vary considerably by indication. The evidence base suggests that a target standard of $2 \%$ for overall capsule retention, irrespective of indication, in any given population is reasonable, with reported overall retention rates of $0.3 \%-3 \%$ $[84,88,113-115]$ and this should be audited yearly.

In all cases of capsule retention within the small bowel, a management plan to promote natural excretion or to retrieve the capsule should be agreed with the patient to avoid subsequent complications, including perforation, obstruction, and bleeding. Most cases of retention do not require surgical intervention. In asymptomatic patients, a "watch and wait" policy, with or without the addition of laxatives, prokinetics, or disease-specific medical therapy, may be a reasonable approach as spontaneous passage of the capsule has been reported in up to $50 \%$ of reported cases [88]. Conversely, symptomatic patients and those with significant small-bowel pathology or with tight stenosis on cross-sectional imaging may benefit from early endoscopic or surgical intervention [115], especially where the pathology is suspected to be malignant.

\section{Domain: Number of procedures}

As a safe non-invasive procedure with high patient acceptability and proven clinical use, the role and demand for SBCE continues to increase; delivering this requires the provision of well trained, competent endoscopists. As with all endoscopy, competency involves a broad knowledge of the procedure, including indications and contraindications, lesion identification and interpretation, accurate reporting, and follow-up, as well as technical and practical skills.

It is well accepted and established that there is a need to combine both formal training courses and supervised practical training for most endoscopy procedures and to perform formal structured assessment before a trainee is considered competent. The small-bowel working group unanimously agreed that completion of a formal training course, compliant with core curriculum recommendations for SBCE, and a minimum number of practical procedural experiences are both needed to become proficient in SBCE. Although there are several studies that show enhanced accuracy with reading experience and confirm the value of formal training courses, the overall evidence base in support of this recommendation is scant. In addition, there is some evidence to show that trainees with prior endoscopy experience are at an advantage in gaining competence and dual training should be encouraged [116].

It is unclear if there is a need to regularly undertake a minimum number of procedures to maintain competency. While this may appear prudent and would be in keeping with recommendations for other flexible endoscopy procedures, there are insufficient data currently to make a recommendation. During the discussions and the Delphi process, the working group agreed on the suggestion that a minimum of $30-50$ SBCEs is required to acquire proficiency and that $30-50$ procedures per year are needed to maintain competence. However, ESGE is currently developing a curriculum for training in small-bowel endoscopy that will address this matter more in detail [117-119].

\section{Performance measures for device-assisted enteroscopy (DAE)}

\section{Domain: Pre-procedure}

\begin{tabular}{|c|c|}
\hline $\begin{array}{l}\text { Key per- } \\
\text { formance } \\
\text { measure }\end{array}$ & Indication for DAE \\
\hline Description & $\begin{array}{l}\text { Percentage of DAEs performed for an appropriate } \\
\text { indication }\end{array}$ \\
\hline Domain & Pre-procedure \\
\hline Category & Process \\
\hline Rationale & $\begin{array}{l}\text { Adherence to appropriate indications for DAE (in } \\
\text { accordance with ESGE guidance) ensures patient safety } \\
\text { (by a reduction of risk associated with unnecessary } \\
\text { procedures), may improve diagnostic and therapeutic } \\
\text { yield, and enhances efficiency relating to appropriate } \\
\text { allocation of limited resources }\end{array}$ \\
\hline
\end{tabular}




\begin{tabular}{|c|c|}
\hline $\begin{array}{l}\text { Key per- } \\
\text { formance } \\
\text { measure }\end{array}$ & Indication for DAE \\
\hline Construct & $\begin{array}{l}\text { Denominator: DAE procedures performed } \\
\text { Numerator: Proportion of DAE procedures performed } \\
\text { for an appropriate indication: } \\
\text { " therapy in patients with positive findings at capsule } \\
\text { endoscopy } \\
\text { " patients with obscure GI bleeding when SBCE is not } \\
\text { available or is contraindicated } \\
\text { - in selected cases of ongoing overt obscure GI bleed- } \\
\text { ing } \\
\text { " patients with ongoing obscure GI bleeding and a un- } \\
\text { remarkable capsule endoscopy } \\
\text { " for biopsy in patients with non-contributory ileoco- } \\
\text { lonoscopy and with suspicion of Crohn's disease on } \\
\text { radiologic imaging tests or capsule endoscopy } \\
\text { - in Crohn's disease patients, when endotherapy is in- } \\
\text { - } \text { dicated } \\
\text { bowen an imaging test shows suspicion of small- } \\
\text { - for biopsy in patients where there is an uncertain di- } \\
\text { agnosis of small-bowel tumor at capsule endoscopy } \\
\text { " when a submucosal mass is detected by capsule } \\
\text { endoscopy } \\
\text { " in patients with inherited polyposis syndromes when } \\
\text { polypectomy is indicated } \\
\text { " in patients with nonresponsive or refractory celiac } \\
\text { disease for biopsy } \\
\text { Exclusions: None } \\
\text { Calculation: Proportion (\%) } \\
\text { Level of analysis: Service level } \\
\text { Frequency: Yearly and/or for a sample of } 50 \text { DAEs }\end{array}$ \\
\hline Standards & $\begin{array}{l}\text { Minimum standard: } \geq 95 \% \\
\text { Target standard: } \geq 95 \% \\
\text { Regular audit should be encouraged to assess if proce- } \\
\text { dures are being performed for recognized indications } \\
\text { After evaluation and adjustment, close monitoring } \\
\text { should be performed with a further audit within } \\
12 \text { months }\end{array}$ \\
\hline $\begin{array}{l}\text { Consensus } \\
\text { agreement }\end{array}$ & $100 \%$ \\
\hline $\begin{array}{l}\text { PICO } \\
\text { number }\end{array}$ & 1 (see Supporting information, DAE) \\
\hline $\begin{array}{l}\text { Evidence } \\
\text { grading }\end{array}$ & Moderate quality evidence \\
\hline
\end{tabular}

The acceptance of this performance measure is based on the agreement with the following statement:

- DAE examinations should be performed for recognized indications as published in international guidelines. (Statement number 19) Agreement: $100 \%$

The small-bowel working group, in line with ESGE guidance (technical and clinical) $[9,10]$, strongly recommends adherence to appropriate indications for DAE. DAE should usually be guided by the findings of less invasive investigations (SBCE and/ or dedicated cross-sectional imaging). As per ESGE guidance, the principal indication for DAE should be for the application of appropriate endotherapy, as clinically indicated, and for clarification of any diagnostic uncertainty through direct endoscopic visualization and biopsy of pathology for histopathological analysis. A "straight to DAE" approach should be reserved for emergency situations, including active small-bowel bleeding [120], using the antegrade route first unless a distal lesion is known to be present [10].

\begin{tabular}{|c|c|}
\hline $\begin{array}{l}\text { Minor per- } \\
\text { formance } \\
\text { measure }\end{array}$ & Proper instructions for bowel preparation \\
\hline Description & $\begin{array}{l}\text { Percentage of patients receiving bowel preparation } \\
\text { instructions appropriately }\end{array}$ \\
\hline Domain & Pre-procedure \\
\hline Category & Process \\
\hline Rationale & $\begin{array}{l}\text { The giving of proper instructions for bowel preparation } \\
\text { before DAE improves small-bowel mucosal visualization } \\
\text { and ensures a safe procedure. Inadequate bowel prepa- } \\
\text { ration results in increased costs and inconvenience due } \\
\text { to the need for a repeat DAE or alternative investigation. } \\
\text { The quality of bowel preparation should be included in } \\
\text { the report }\end{array}$ \\
\hline Construct & $\begin{array}{l}\text { Denominator: Patients undergoing DAE } \\
\text { Numerator: Patients in the denominator receiving } \\
\text { proper bowel preparation instructions: } \\
\text { - For antegrade DAE: } \\
\text { - fasting for solids for at least } 6 \text { hours prior to the } \\
\text { procedure } \\
\text { - patients are allowed to take water until } 2 \text { hours } \\
\quad \text { prior to the procedure } \\
\text { - For retrograde DAE: } \\
\text { - - same regimen of preparation as recommended } \\
\quad \text { lene glycol-based regimens of preparation) } \\
\text { Exclusions: Emergency DAE, patients with ongoing } \\
\text { bleeding } \\
\text { Calculation: Proportion (\%) } \\
\text { Level of analysis: Service and individual level } \\
\text { Frequency: Yearly and/or for a sample of } 100 \text { DAEs }\end{array}$ \\
\hline Standards & $\begin{array}{l}\text { Minimum standard: } \geq 95 \% \\
\text { Target standard: } \geq 95 \% \\
\text { If the minimum standard is not reached, analysis of the } \\
\text { factors that influence proper information about bowel } \\
\text { preparation (information given to patients, dietary } \\
\text { restrictions, fasting, cleansing agents used, timing) } \\
\text { should be performed on a service level } \\
\text { After evaluation and adjustment, close monitoring } \\
\text { should be performed with a further audit within } \\
12 \text { months }\end{array}$ \\
\hline $\begin{array}{l}\text { Consensus } \\
\text { agreement }\end{array}$ & $91.6 \%$ \\
\hline $\begin{array}{l}\text { PICO num- } \\
\text { ber }\end{array}$ & 2 (see Supporting information, DAE file) \\
\hline $\begin{array}{l}\text { Evidence } \\
\text { grading }\end{array}$ & Low quality evidence \\
\hline
\end{tabular}


The acceptance of this performance measure is based on the strength of agreement with the following statements:

- All patients (100\%) undergoing DAE should receive adequate pre-procedure preparation, including fasting for antegrade DAE and approved bowel preparation for retrograde DAE. (Statement number 18) Agreement: 100\%

- All patients (100\%) referred for antegrade DAE should be fasting for solids for at least 6 hours prior to the procedure. (Statement number 18.1) Agreement: 88.9\%

- All patients (100\%) referred for antegrade DAE are allowed to take water until 2 hours prior to the procedure. (Statement number 18.2) Agreement: 88.9\%

- All patients (100\%) referred for retrograde DAE should follow the same regimen of preparation as recommended by ESGE guidelines for colonoscopy. (Statement number 18.3) Agreement: $88.9 \%$

The small-bowel working group, in line with ESGE guidance (technical and clinical) $[9,10]$, strongly recommends adherence to appropriate preparation instructions for DAE. As for other endoscopic procedures [121], good quality preparation is essential for adequate detection of small-bowel mucosal pathology at DAE. Additionally, particularly in the case of retrograde DAE procedures, the presence of intraluminal debris is not only detrimental to lesion identification but also to the technical success of procedures as this may lead to excessive friction between the enteroscope and overtube, causing hindrance to the progress of the procedure. Although there are no comparative studies on preparation for antegrade DAE [122 - 125], a prolonged fast of at least 6 hours is usually sufficient. Retrograde DAE procedures require optimal, purgativebased preparation as per the local protocol for colonoscopy [126, 127].

The presence or suspicion of a stenosis may potentially increase the risk of residual intraluminal debris and, in such cases, more prolonged fasting (and potentially additional preparation) may be required [10].

\section{Domain: Completeness of procedure}

\begin{tabular}{|c|c|}
\hline $\begin{array}{l}\text { Key per- } \\
\text { formance } \\
\text { measure }\end{array}$ & Tattooing of the point of maximal insertion depth \\
\hline Description & $\begin{array}{l}\text { Proportion of cases with tattooing of the point of } \\
\text { maximal insertion depth }\end{array}$ \\
\hline Domain & Completeness of procedure \\
\hline Category & Process \\
\hline Rationale & $\begin{array}{l}\text { DAE is intended for diagnosis and treatment of small- } \\
\text { bowel pathology. In some patients, a combined oral } \\
\text { and anal approach may be indicated. Tattooing the } \\
\text { point of maximal insertion at the initial DAE is useful in } \\
\text { order to confirm complete small-bowel examination } \\
\text { (panenteroscopy) at the subsequent DAE (performed } \\
\text { through the alternative route of approach). It is also } \\
\text { useful to mark pathology }\end{array}$ \\
\hline
\end{tabular}

\begin{tabular}{|c|c|}
\hline $\begin{array}{l}\text { Key per- } \\
\text { formance } \\
\text { measure }\end{array}$ & Tattooing of the point of maximal insertion depth \\
\hline Construct & $\begin{array}{l}\text { Denominator: Patients undergoing DAE } \\
\text { Numerator: Patients in whom the extent of insertion } \\
\text { has been marked with a tattoo on initial DAE } \\
\text { Exclusions: None } \\
\text { Calculation: Proportion (\%) } \\
\text { Level of analysis: Service and individual level } \\
\text { Frequency: Yearly and/or for a sample of } 100 \text { DAEs }\end{array}$ \\
\hline Standards & $\begin{array}{l}\text { Minimum standard: } \geq 80 \% \\
\text { Target standard: } \geq 80 \% \\
\text { Tattooing rates should be audited based on intention } \\
\text { to treat. Tattooing should be performed in at least } 80 \% \\
\text { of cases }\end{array}$ \\
\hline $\begin{array}{l}\text { Consensus } \\
\text { agreement }\end{array}$ & $100 \%$ \\
\hline $\begin{array}{l}\text { PICO num- } \\
\text { ber }\end{array}$ & 6 (see Supporting information, DAE file) \\
\hline $\begin{array}{l}\text { Evidence } \\
\text { grading }\end{array}$ & Very low quality of evidence \\
\hline
\end{tabular}

The acceptance of this performance measure is based on the strength of agreement with the following statement:

- Depth of insertion should be marked with a submucosal tattoo of sterile carbon particles. (Statement number 24.1) Agreement: $100 \%$

On meta-analysis and pooled analysis of randomized studies, the pooled panenteroscopy rate was $44 \%$ by combined or antegrade-only approach [128] and was superior for double-balloon enteroscopy (DBE; $50 \%$ ) as compared with single-balloon enteroscopy (SBE) in four pooled randomized trials [129]. Reaching a previously placed submucosal tattoo is the only way of confirming panenteroscopy when both an antegrade and retrograde approach are required to achieve this. Although reports of randomized studies from Asian countries report a high percentage of panenteroscopy, the experience may be radically different in other (mainly Western) centers, as panenteroscopy is rarely the objective of the examination (probably confined mostly to cases of diagnostic enteroscopy without previous SBCE). Heterogeneity among different centers and countries is evident; this may reflect the fact that in Western countries, SBCE is almost always used as a screening test prior to DAE, so avoiding the need for panenteroscopy.

\begin{tabular}{|l|l|}
\hline $\begin{array}{l}\text { Minor per- } \\
\text { formance } \\
\text { measure }\end{array}$ & Reporting the depth of insertion \\
\hline Description & Proportion of reports stating extent of insertion \\
\hline Domain & Completeness of procedure \\
\hline Category & Process \\
\hline
\end{tabular}




\begin{tabular}{|c|c|}
\hline $\begin{array}{l}\text { Minor per- } \\
\text { formance } \\
\text { measure }\end{array}$ & Reporting the depth of insertion \\
\hline Rationale & $\begin{array}{l}\text { DAE is intended for the diagnosis and treatment of } \\
\text { small-bowel pathology. DAE is usually performed fol- } \\
\text { lowing a less invasive small-bowel investigation (i. e. } \\
\text { SBCE and/or dedicated cross-sectional imaging) that } \\
\text { has demonstrated significant pathology. An estimation } \\
\text { of insertion depth allows comparison of the site of the } \\
\text { lesion identified at DAE with that estimated on the pre- } \\
\text { ceding investigation(s) and may also serve as a guide } \\
\text { during surgery should this be required }\end{array}$ \\
\hline Construct & $\begin{array}{l}\text { Denominator: Patients undergoing DAE } \\
\text { Numerator: Patients in whom the extent of insertion is } \\
\text { estimated and reported } \\
\text { Exclusions: None } \\
\text { Calculation: Proportion (\%) } \\
\text { Level of analysis: Service and individual level } \\
\text { Frequency: Yearly and/or for a sample of } 100 \text { DAEs }\end{array}$ \\
\hline Standards & $\begin{array}{l}\text { Minimum standard: } \geq 80 \% \\
\text { Target standard: } \geq 80 \% \\
\text { An estimation of the depth of insertion (e. g. depth in } \\
\mathrm{cm} \text { ) should be included in the report }\end{array}$ \\
\hline $\begin{array}{l}\text { Consensus } \\
\text { agreement }\end{array}$ & $90.9 \%$ \\
\hline $\begin{array}{l}\text { PICO } \\
\text { number }\end{array}$ & 6 (see Supporting information, DAE file) \\
\hline $\begin{array}{l}\text { Evidence } \\
\text { grading }\end{array}$ & Very low quality of evidence \\
\hline
\end{tabular}

The acceptance of this performance measure is based on the strength of agreement with the following statement:

- In all cases, small-bowel depth of insertion should be estimated and recorded. (Statement number 24) Agreement: $90.9 \%$

This statement corresponds to a very low level of evidence because of the low reliability of measurement of small-bowel insertion depth. The only scientific approach is that described by May et al. [124], who validated an estimated 40-cm progression for each insertion step; however, clinical experience suggests that this measure is still rather uncertain, given the episodic "slippage" (where previous advancement is "lost" by enteroscope and overtube "fallback") and episodic failure of advancement, which are encountered at some point during all DAE procedures. Despite animal studies showing a low deviation $(<10 \%)$ from the actual and calculated insertion depth $[124,130]$, in actual clinical practice, there is a large variation in the techniques employed, in enteroscopist ability, and procedure efficacy, with human studies failing to confirm the earlier animal studies. Therefore, the impact of this measure on diagnostic yield at DAE is unknown.

\section{Domain: Identification of pathology}

\begin{tabular}{|c|c|}
\hline $\begin{array}{l}\text { Key per- } \\
\text { formance } \\
\text { measure }\end{array}$ & Lesion detection rate \\
\hline Description & Percentage of DAEs with detected pathology \\
\hline Domain & Identification of pathology \\
\hline Category & Process \\
\hline Rationale & $\begin{array}{l}\text { Patients for DAE should be carefully selected to maxi- } \\
\text { mize diagnostic yield. Overall pathology detection rates } \\
\text { for SBCE and DAE vary according to indication. The in- } \\
\text { dications for both SBCE and DAE procedures should be } \\
\text { regularly audited with adherence to guidelines; reasons } \\
\text { for variation should be examined }\end{array}$ \\
\hline Construct & $\begin{array}{l}\text { Denominator: All patients undergoing DAE } \\
\text { Numerator: Patients undergoing DAE for an appropri- } \\
\text { ate clinical indication, as stated in recognized clinical } \\
\text { guidelines (e.g. ESGE), where pathology is detected } \\
\text { Exclusions: None } \\
\text { Calculation: Proportion (\%) } \\
\text { Level of analysis: Service and individual level } \\
\text { Frequency: Yearly and/or for a sample of } 100 \text { DAEs }\end{array}$ \\
\hline Standards & $\begin{array}{l}\text { Minimum standard: } \geq 50 \% \\
\text { Target standard: } \geq 50 \% \\
\text { Indication for DAE should be reported for all procedures } \\
\text { If the minimum standard is not reached, analysis of } \\
\text { the factors influencing patient selection should be } \\
\text { performed } \\
\text { After evaluation and adjustment, close monitoring } \\
\text { should be performed with a further audit within } 12 \\
\text { months }\end{array}$ \\
\hline $\begin{array}{l}\text { Consensus } \\
\text { agreement }\end{array}$ & $96.3 \%$ \\
\hline $\begin{array}{l}\text { PICO } \\
\text { numbers }\end{array}$ & 5,7 , and 8 (see Supporting information, DAE file) \\
\hline $\begin{array}{l}\text { Evidence } \\
\text { grading }\end{array}$ & Very low quality of evidence \\
\hline
\end{tabular}

The acceptance of this performance measure is based on the agreement with the following statements:

- Cases for DAE should be carefully selected to maximize diagnostic yield. (Statement number 21) Agreement: 88.9\%

- Current literature is insufficient to set a minimum diagnostic yield for DAE by indication or per enteroscopist. DAE use and diagnostic yield should be audited regularly. (Statement number 22) Agreement: $100 \%$

- Overall pathology detection rates for SBCE and DAE vary according to indication. Indications for both SBCE and DAE procedures should be regularly audited for adherence to international guidelines and reasons for variations should be examined. (Statement number 23) Agreement: 100\%

Appropriate detection and management of pathology is one of the cornerstones of quality in endoscopy. Reducing lesion "miss rates" results in improved patient outcomes and warrants consideration as a specific quality measure. 
DAE is most often performed following a less invasive smallbowel investigation (SBCE and/or dedicated cross-sectional imaging) and is therefore undertaken following identification of pathology and with a specific therapeutic intent. This approach is favored, where possible, and can assist with planning the appropriate approach route (antegrade or retrograde), as well as the appropriate intervention. In such cases, correlation between the expected and achieved lesion detection rates, and the proportion of successful interventions are likely to prove useful performance measures, reflecting appropriate patient selection and operator competency.

In general, unlike adenoma detection rate in screening colonoscopy, there is inadequate evidence available in the literature to support a recommendation of specific overall diagnostic yield for DAE, with significant variation in reported diagnostic yields from $47 \%$ to $75 \%[2,4,63-64,95,97]$.

As with other endoscopic modalities, published evidence confirms lesion detection and diagnostic yield vary according to indication, further affecting the ability to set specific quality targets for DAE. In addition, the route of DAE affects identification of pathology, with lower rates in general reported for retrograde procedures [81,93].

As such, in the absence of specific targets for overall and per-indication lesion detection rates, to maintain quality, DAE should be performed only for approved clinical indications. ESGE guidelines recommend DAE: for therapy in patients with positive findings at capsule endoscopy; in patients with obscure GI bleeding when SBCE is not available or is contraindicated; in selected patients with ongoing overt obscure Gl bleeding; in patients with ongoing obscure Gl bleeding and an unremarkable capsule endoscopy; for biopsy in patients with noncontributory ileocolonoscopy and a suspicion of Crohn's disease on radiologic imaging tests or capsule endoscopy; in patients with Crohn's disease when endotherapy is indicated; for biopsy and/or tattooing when an imaging test is suspicious of a small-bowel tumor; for biopsy and/or tattooing in patients where there is an uncertain diagnosis of small-bowel tumor at capsule endoscopy; when a submucosal mass is detected by capsule endoscopy; in patients with inherited polyposis syndromes when polypectomy is indicated; in patients with nonresponsive or refractory celiac disease for biopsy.

The proportion of DAE procedures undertaken for an approved indication in a department and by individual enteroscopists should be regularly audited as a quality measure. Any variance should be examined and practice revised to achieve $\geq 95 \%$ compliance (see Domain 7, Appropriate indications for DAE).

\begin{tabular}{|c|c|}
\hline $\begin{array}{l}\text { Minor per- } \\
\text { formance } \\
\text { measure }\end{array}$ & Accurate photodocumentation \\
\hline Description & $\begin{array}{l}\text { Proportion of cases with accurate photo- } \\
\text { documentation of detected lesions }\end{array}$ \\
\hline Domain & Identification of pathology \\
\hline Category & Process \\
\hline Rationale & $\begin{array}{l}\text { It is recommended that photodocumentation is } \\
\text { used to record findings in all DAE cases }\end{array}$ \\
\hline
\end{tabular}

\begin{tabular}{|c|c|}
\hline $\begin{array}{l}\text { Minor per- } \\
\text { formance } \\
\text { measure }\end{array}$ & Accurate photodocumentation \\
\hline Construct & $\begin{array}{l}\text { Denominator: All patients undergoing DAE with } \\
\text { pathology/lesions detected } \\
\text { Numerator: Patients undergoing DAE with photo- } \\
\text { documentation of identified pathology/lesions } \\
\text { detected } \\
\text { Exclusions: None } \\
\text { Calculation: Proportion (\%) } \\
\text { Level of analysis: Service and individual level } \\
\text { Frequency: Yearly and/or for a sample of } 100 \text { DAEs }\end{array}$ \\
\hline Standards & $\begin{array}{l}\text { Minimum standard: } \geq 95 \% \\
\text { Target standard: } \geq 95 \% \\
\text { After evaluation and adjustment, close } \\
\text { monitoring should be performed with a further } \\
\text { audit within } 12 \text { months }\end{array}$ \\
\hline $\begin{array}{l}\text { Consensus } \\
\text { agreement }\end{array}$ & $90.9 \%$ \\
\hline PICO number & 6 (see Supporting information, DAE file) \\
\hline $\begin{array}{l}\text { Evidence } \\
\text { grading }\end{array}$ & Very low quality of evidence \\
\hline
\end{tabular}

The acceptance of this performance measure is based on the agreement with the following statement:

- It is recommended to use photodocumentation as a record of findings in all cases. (Statement number 24.3) Agreement: $90.9 \%$

Endoscopic image documentation has become a routine part of clinical care and has gained an important role in quality control, with many international societies advocating documentation of specific landmarks and pathological lesions. Despite the lack of specific data in support of this approach, there was almost unanimous agreement among experts and in quality recommendations that photodocumentation reflects current best practice, is clinically useful, and can be considered a standard performance measure.

A formal set of photographic images to confirm cecal intubation on reports is the best example of photodocumentation as a quality measure, regarded by many as an essential tool to assess individual and institutional colonoscopy quality. Documentation of other endoscopic landmarks, both in upper and lower $\mathrm{Gl}$ disease, is also advocated and is becoming established practice.

While there are few small-bowel anatomical landmarks and none likely to be viable as DAE quality indicators, taking a photographic record of individual lesions, as done with other endoscopic procedures, is strongly advised. Photodocumentation of lesions facilitates accurate reporting and interpretation, assists with onward referral, and enables direct comparison if subsequent follow-up procedures are required. As such, regular audit and a minimum compliance of $95 \%$ is recommended for lesion photodocumentation as a quality performance measure for DAE. 


\section{Domain: Management of pathology}

\begin{tabular}{|c|c|}
\hline $\begin{array}{l}\text { Key perform- } \\
\text { ance measure }\end{array}$ & Tattooing of detected/treated lesions \\
\hline Description & $\begin{array}{l}\text { Percentage of patients with marking of lesions } \\
\text { intended for further treatment }\end{array}$ \\
\hline Domain & Management of pathology \\
\hline Category & Process \\
\hline Rationale & $\begin{array}{l}\text { It is recommended practice to mark a lesion (with a } \\
\text { submucosal tattoo of sterile carbon particles) when } \\
\text { further intervention is intended }\end{array}$ \\
\hline Construct & $\begin{array}{l}\text { Denominator: Patients undergoing DAE in whom a } \\
\text { lesion is detected and surgical treatment or endo- } \\
\text { scopic resection is intended } \\
\text { Numerator: Patients in the denominator with } \\
\text { tattooing of the lesion } \\
\text { Exclusions: None } \\
\text { Calculation: Proportion (\%) } \\
\text { Level of analysis: Service and individual level } \\
\text { Frequency: Yearly and/or for a sample of } 100 \text { DAEs }\end{array}$ \\
\hline Standards & $\begin{array}{l}\text { Minimum standard: } \geq 95 \% \\
\text { Target standard: } 100 \% \\
\text { If the minimum standard is not reached, the reasons } \\
\text { for this should be explored on a service level } \\
\text { After evaluation and adjustment, close monitoring } \\
\text { should be performed with a further audit within } \\
12 \text { months }\end{array}$ \\
\hline $\begin{array}{l}\text { Consensus } \\
\text { agreement }\end{array}$ & $100 \%$ \\
\hline PICO number & 6 (see Supporting information, DAE file) \\
\hline $\begin{array}{l}\text { Evidence } \\
\text { grading }\end{array}$ & Very low quality of evidence \\
\hline
\end{tabular}

The acceptance of this performance measure is based on agreement with the following statement:

- It is recommended practice to mark a lesion that may later be a target for therapeutic intervention. (Statement number 24.2) Agreement: $100 \%$

Therapeutic DAE is indicated when small-bowel lesions are detected by SBCE or dedicated radiological imaging [9], as well as when there is a high probability of endotherapy requirement in patients presenting with recurrent known small-bowel disease, including angioectasia or other vascular lesions, polyposis syndromes, and strictures. DAE facilitates all endotherapy, including hemostasis, lesion resection, endoscopic balloon dilation of strictures, direct percutaneous endoscopic jejunostomy tube placement, and endoscopic retrograde cholangiopancreatography (ERCP) in patients with altered anatomy. It also enables biopsy for histopathological analysis and tattooing of lesions for minimally invasive surgical management.

\begin{tabular}{|c|c|}
\hline $\begin{array}{l}\text { Minor per- } \\
\text { formance } \\
\text { measure }\end{array}$ & Successful therapeutic intervention \\
\hline Description & $\begin{array}{l}\text { Proportion of patients undergoing successful } \\
\text { therapeutic intervention }\end{array}$ \\
\hline Domain & Management of pathology \\
\hline Category & Process \\
\hline Rationale & $\begin{array}{l}\text { Therapeutic DAE is indicated when small-bowel } \\
\text { lesions are detected by SBCE or other radiological } \\
\text { imaging techniques. It is recommended practice to } \\
\text { monitor the technical success in those cases where a } \\
\text { therapeutic maneuver is intended }\end{array}$ \\
\hline Construct & $\begin{array}{l}\text { Denominator: Patients undergoing a planned } \\
\text { therapeutic DAE } \\
\text { Numerator: Patients in the denominator in which } \\
\text { the foreseen therapeutic intervention could be com- } \\
\text { pletely performed } \\
\text { Exclusions: None } \\
\text { Calculation: Proportion (\%) } \\
\text { Level of analysis: Service and individual level } \\
\text { Frequency: Yearly and/or for a sample of } 100 \text { DAEs }\end{array}$ \\
\hline Standards & $\begin{array}{l}\text { Minimum standard: } \geq 80 \% \\
\text { Target standard: } \geq 80 \% \\
\text { Intervention rates should be audited based on inten- } \\
\text { tion to treat, including targeted biopsies and planned } \\
\text { interventions, and technical success should be } \\
\text { achieved in at least } 80 \% \text { of cases } \\
\text { After evaluation and adjustment, close monitoring } \\
\text { should be performed with a further audit within } \\
12 \text { months }\end{array}$ \\
\hline $\begin{array}{l}\text { Consensus } \\
\text { agreement }\end{array}$ & $88.9 \%$ \\
\hline PICO number & 5 (see Supporting information, DAE file) \\
\hline $\begin{array}{l}\text { Evidence } \\
\text { grading }\end{array}$ & Very low quality of evidence \\
\hline
\end{tabular}

The acceptance of this performance measure is based on agreement with the following statement:

- Intervention rates should be audited based on an intent to treat basis and successful completion of the planned intervention or outcomes should be achieved in at least $80 \%$ of cases. (Statement number 21) Agreement: $88.9 \%$

Although data on intended versus actual intervention rates for DAE are lacking, based on the available evidence and expert opinion, a target rate of $80 \%$ was considered appropriate by the working group. If the minimum standard is not achieved on a case-by-case basis, audit should be performed including review of the operator's DAE technique, as well as a critical review of the initial diagnostic tests, SBCE, or radiology that prompted the DAE procedure. It should also be be borne in mind that insertion depth is frequently only a rough estimate, so an apparent lack of success may be due to the lesion not being reached. In addition, once identified, as previously stres- 
sed, a tattoo-based marking of the lesion location is required to facilitate further intervention.

\section{Domain: Complications}

\begin{tabular}{|c|c|}
\hline $\begin{array}{l}\text { Key per- } \\
\text { formance } \\
\text { measure }\end{array}$ & $\begin{array}{l}\text { Rate of complications for diagnostic and } \\
\text { therapeutic DAE procedures }\end{array}$ \\
\hline Description & $\begin{array}{l}\text { Percentage of patients undergoing diagnostic and } \\
\text { therapeutic DAE who experience a significant compli- } \\
\text { cation } \\
\text { Complication rate (overall, including perforation, } \\
\text { bleeding, and pancreatitis) resulting from diagnostic } \\
\text { and therapeutic DAE should not exceed } 1 \% \text { and } 5 \% \text {, } \\
\text { respectively, in an unselected population }\end{array}$ \\
\hline Domain & Complications \\
\hline Category & Outcome / Process \\
\hline Rationale & $\begin{array}{l}\text { Monitoring for complications is essential to ensure } \\
\text { the safety of the procedure }\end{array}$ \\
\hline Construct & $\begin{array}{l}\text { Denominator: Patients undergoing DAE } \\
\text { Numerator: Patients in the denominator experiencing } \\
\text { a complication (perforation, bleeding, or pancreatitis) } \\
\text { Exclusions: None } \\
\text { Calculation: Proportion (\%) } \\
\text { Level of analysis: Service and individual level } \\
\text { Frequency: Yearly and/or for a sample of } 100 \text { DAEs }\end{array}$ \\
\hline Standards & $\begin{array}{l}\text { Minimum standard: }<5 \% \\
\text { Target standard: }<5 \% \\
\text { If the minimum standard is not reached, analysis of } \\
\text { the factors influencing complication rate (including } \\
\text { assessment of operator numbers, operator experience, } \\
\text { case complexity, presence of previous small-bowel } \\
\text { surgery, and underlying pathology) should be per- } \\
\text { formed on an individual and service level } \\
\text { After evaluation and adjustment, close monitoring } \\
\text { should be performed with a further audit within } \\
12 \text { months }\end{array}$ \\
\hline $\begin{array}{l}\text { Consensus } \\
\text { agreement }\end{array}$ & $100 \%$ \\
\hline $\begin{array}{l}\text { PICO num- } \\
\text { bers }\end{array}$ & 16,18 (see Supporting information, DAE file) \\
\hline $\begin{array}{l}\text { Evidence } \\
\text { grading }\end{array}$ & Moderate quality evidence \\
\hline
\end{tabular}

The acceptance of this performance measure is based on the strength of agreement with the following statements:

- The rate of severe complications (overall, including perforation, bleeding, and pancreatitis) resulting from diagnostic DAE should not exceed $1 \%$ in an unselected population.

(Statement number 26) Agreement: 100\%

- The rate of severe adverse events (overall, including perforation, bleeding, and pancreatitis) resulting from therapeutic DAE should not exceed $5 \%$ in an unselected population. (Statement number 26.1) Agreement: $100 \%$

- The overall rate of pancreatitis in DAE should not exceed $0.3 \%$. (Statement number 26.2) Agreement: $88.9 \%$
- Adverse event rates by operator and indication should be audited for all DAE procedures against known rates of adverse events. Reasons for variations from these rates should be examined. (Statement number 27) Agreement: 100\%

DAE is a safe procedure: the complication rates for DAE from published pooled series indicate that the complication rate for diagnostic procedures is $<1 \%$ and for therapeutic procedures is $<5 \%$. There are limited data to suggest that the complication rate is greater in patients who have had previous abdominal surgery resulting in altered bowel anatomy, especially with the retrograde route, and caution is advised when performing the procedure in this group of patients. A meta-analysis by Lipka et al. [130] showed that complication rates of SBE and DBE were similar (overall adverse events: relative risk $1.41,95 \% \mathrm{Cl}$ $0.32-6.3 ; P=0.65)$. Pancreatitis is a recognized procedurerelated complication of DAE (especially antegrade) and warrants specific mention. Techniques to avoid ampullary trauma and pancreatic injury should be employed for all DAE procedures. Based on the available data, the overall rate of pancreatitis in DAE should not exceed $0.3 \%$.

\section{Domain: Number of procedures}

In the absence of any evidence regarding the number of procedures required for training for individual certification of DAE competence, we were not able to set any minimum standard. Any recommendation in terms of the minimum annual number of procedures per endoscopist that are required to maintain adequate levels of quality, as well as which kind of training should be provided to beginners and/or to poor performers, would need to be based on an established strong association of poor quality with a minimum threshold number of procedures performed per year. Such data are currently unavailable. Nevertheless, after an extensive discussion the working group agreed the following suggestion: (i) training should only be provided by experienced enteroscopists in units with a sufficient volume of work (50-100/year) to ensure an appropriate case mix, and trainee proficiency should be assessed by direct observation of procedures prior to being signed off by their supervisor; (ii) combined training in capsule endoscopy and DAE may enhance lesion recognition and detection, and is encouraged in those intending to perform DAE.

Definitive data regarding the need for training and its potential benefits on diagnostic accuracy are lacking. In fact, there are no formal guidelines that state the minimum training requirements before performing DAE. According to an unpublished expert consensus on DBE, only advanced trainees should train in DAE. Advanced endoscopy skills should mean having enough experience in both diagnostic and therapeutic endoscopy, including hemostasis (endoclipping, argon plasma coagulation, and injection endotherapy), polypectomy and lesion resection, endoscopic balloon dilation, stenting, and/or ERCP. This approach is also supported by a recent trial conducted in high volume centers in Japan, which demonstrated that DBE can be safely carried out by advanced trainees under the supervision of an expert after a dedicated training program [131]. 
Based on available early publications, although performance will vary according to the individual's endoscopic skillset, at least 10 - 15 cases performed under expert supervision are necessary to achieve appreciable small-bowel insertion depth for antegrade DAE procedures. The retrograde insertion route is usually found to be more challenging and at least $30-35$ cases are needed to achieve an appreciable, effective insertion depth [132 - 133]. However, these numbers are likely to be an underestimate of the experience required to achieve actual, effective clinical competence and the lack of a solid evidence base should be noted in this regard. The impact of SBCE knowledge and experience in DAE training remains unknown and warrants further study; albeit, it may reduce the training period as lesion appearance is similar for both modalities.

\section{Domain: Patient experience}

\begin{tabular}{|c|c|}
\hline $\begin{array}{l}\text { Key per- } \\
\text { formance } \\
\text { measure }\end{array}$ & Patient comfort \\
\hline Description & $\begin{array}{l}\text { Patient comfort should be audited for all DAE } \\
\text { procedures using a validated comfort score }\end{array}$ \\
\hline Domain & Patient experience \\
\hline Category & Outcome / Process \\
\hline Rationale & $\begin{array}{l}\text { Patient comfort is a surrogate marker for quality of the } \\
\text { procedure. There are considerable differences among } \\
\text { enteroscopists, equipment, techniques, and among } \\
\text { different sedation protocols with regards to patient- } \\
\text { reported pain and discomfort }\end{array}$ \\
\hline Construct & $\begin{array}{l}\text { Denominator: Patients undergoing DAE } \\
\text { Numerator: Patients in the denominator with recorded } \\
\text { and reported comfort score } \\
\text { Exclusions: None } \\
\text { Calculation: Proportion (\%) } \\
\text { Level of analysis: Service and individual level } \\
\text { Frequency: Yearly and/or for a sample of } 100 \text { DAEs }\end{array}$ \\
\hline \multirow[t]{2}{*}{ Standards } & $\begin{array}{l}\text { Minimum standard: unknown } \\
\text { Target standard: } \geq 90 \%\end{array}$ \\
\hline & $\begin{array}{l}\text { Currently there is no gold-standard approach to } \\
\text { measuring patient experience: different questionnaires } \\
\text { are available and their comparative performance is } \\
\text { unclear. Ideally, patient experience should be self- } \\
\text { reported and/or recorded by the endoscopist/nurse } \\
\text { using a standardized and validated reporting method. } \\
\text { Audits should be performed on both service and indi- } \\
\text { vidual endoscopist levels to assess patient experience } \\
\text { In case of substandard levels, analysis of the factors } \\
\text { influencing comfort (including assessment of operator } \\
\text { numbers, operator experience, case complexity, and } \\
\text { technique) should be performed on an individual and } \\
\text { service level } \\
\text { After evaluation and adjustment, close monitoring } \\
\text { should be performed with a further audit within } \\
12 \text { months }\end{array}$ \\
\hline $\begin{array}{l}\text { Consensus } \\
\text { agreement }\end{array}$ & $90.9 \%$ \\
\hline $\begin{array}{l}\text { PICO } \\
\text { number }\end{array}$ & 21, 24 (see Supporting information, DAE file) \\
\hline
\end{tabular}

\begin{tabular}{|l|l|}
\hline $\begin{array}{l}\text { Key per- } \\
\text { formance } \\
\text { measure }\end{array}$ & Patient comfort \\
\hline $\begin{array}{l}\text { Evidence } \\
\text { grading }\end{array}$ & Moderate quality evidence \\
\hline
\end{tabular}

The acceptance of this performance measure is based on the strength of agreement with the following statements:

- Patient comfort should be audited for all DAE procedures. (Statement number 28) Agreement: 90.9\%

- Inadequate comfort levels should be audited against route of insertion, sedation, insufflation method, and endoscopist experience. (Statement number 29) Agreement: 90.9\%

Patient comfort is a surrogate marker for procedure quality. Monitoring patient experience is feasible, yet it is not universal, and no standardized approach exists. The Global Rating Scale (GRS) [134-135] is the most validated questionnaire for assessing patient experience. Comfort of patients undergoing DAE is related to enteroscopist competence, available equipment, sedation protocol, and overall setup.

Three meta-analyses [136-138] have demonstrated that the use of $\mathrm{CO}_{2}$ insufflation, when compared with air, is associated with reduced abdominal discomfort as measured on a visual analogue scale (VAS) for pain assessment at 1 hour $(P=0.015)$, 3 hours $(P=0.04)$, and 6 hours $(P=0.03)$ following the procedure. A lower mean dose of propofol needed for the procedure favored $\mathrm{CO}_{2}$ compared with air insufflation $(P=0.002)$. Although these systematic reviews have limitations, the routine use of $\mathrm{CO}_{2}$ is recommended whilst further evidence is gathered.

\section{Future research}

The potential areas needing future research in SBCE and DAE are broad, encompassing the pre-procedure, procedure, and post-procedure domains, and all research designed to address quality issues is to be encouraged and welcomed. However, through the process of developing these recommendations, important areas pertinent to procedure quality with an insufficient evidence base were highlighted, which in our opinion warrant particular mention. Future research is required to address these issues, to strengthen the evidence base, and thereby support the refinement of some of the quality measures and the development of new ones going forward.

In relation to capsule endoscopy, the timing, selection, and use of different bowel preparation combinations remains an issue. Despite numerous publications and several meta-analyses, the optimal approach to enhance not only visualization but also procedure completion and lesion detection in all patients and in those at risk of a poor quality procedure remains debatable.

In addition to preparation, an acceptable diagnostic yield remains inconclusive for capsule endoscopy overall and for any given indication. As there is no true gold-standard comparator for capsule endoscopy, it is difficult to define its accuracy. While correlation with subsequent DAE or surgery and long- 
term longitudinal follow-up studies offer some form of accuracy assessment, a robust approach to defining acceptable diagnostic tolerances for capsule endoscopy is required.

Similarly, diagnostic accuracy in capsule endoscopy is heavily reliant on individual reader and reading mode characteristics, but is without a simple measure to assess performance. As such, studies on reading and reader-related parameters (reading speeds, enhanced reading technologies, reader experience, prior training, reading/caseload volume, as well as novel parameters) should be a focus of future research.

With regard to DAE, further studies to help define accuracy are also needed. As with capsule endoscopy, currently there are no gold standards with which to compare DAE. There is no clear definition of a complete DAE, and no true understanding of the value of a negative diagnostic DAE or the likelihood of missed lesions overall or for any given indication. While comparisons with capsule endoscopy and radiology can be helpful, they are not without potential flaws and a more robust approach to accuracy assessment is required.

As with other endoscopy procedures, DAE is operatordependent and a clearer idea of the optimal training, competency assessment tools, including key performance indices, and the impact of experience and case-load are needed.

Finally, within the DAE arena there is a need to understand the advantages and disadvantages of different devices and their approaches, and to develop appropriate recommendations, if warranted, for their selection in a given clinical scenario, along with the development of specific quality measures where necessary.

\section{Supporting information}

The detailed literature searches performed by an expert team of methodologists, as well as evolution and adaptation of the different PICOs and clinical statements during the Delphi voting process, can be viewed in Supporting Information on the ESGE website.

Online content viewable at: https://www.esge.com/

performance-measures-for-small-bowel-endoscopy.html.

\section{Acknowledgments}

The authors gratefully acknowledge the contributions from: Dr. Stuart Gittens, ECD Solutions in the development and running of the web platform; all at Hamilton Services for project administrative support; the Scottish Intercollegiate Guidelines Network for hosting the critical appraisal module; and the Research Foundation-Flanders (FWO) for providing funding for Professor Raf Bisschops. UEG supplied co-funding and additional project governance to this endeavor.

\section{Competing interests}

S. Adler gives teaching seminars in capsule endoscopy sponsored by Medtronic (2015 to present). C. Bennett owns and works for Systematic Research Ltd., and received a consultancy fee from ESGE to provide scientific, technical, and methodological expertise for the present project (2014-2018). R. Bisschops has received: speaker's fees from Covidien (2009-2014) and Fujifilm (2013); speaker's fee and hands-on training sponsorship from Olympus Europe (20132014); speaker's fee and research support from Pentax Europe; and an editorial fee from Georg Thieme Verlag as co-editor of Endoscopy. M. Bretthauer receives fees for being a member of the Norwegian government CRC screening advisory group (2012 to present) and receives funds from the American College of Physicians for editorial work for Annals of Internal Medicine. E. Despott has received honoraria from Fujifilm and Olympus (2017 - 2019) and academic and research funding from Fujifilm, Olympus, and Pentax Medical (2017-2019). M. Dinis-Ribeiro receives funds from Georg Thieme Verlag for editorial work for Endoscopy. I. Fernández-Urién receives consultancy fees from Given Imaging, Covidien, and Medtronic (2010-2018). M. Kaminski receives speakers and teaching fees and travel support from Olympus Erbe. M. Keuchel has received speaker fees from Medtronic and Olympus (2002-2019), Given Imaging study support (20102013), and DGVS-guideline quality in endoscopy (2012-2015). M. McAlindon receives consultancy fees from Medtronic (20162019) and receives research support from Ankon Ltd. and Intromedic Ltd. (2017 - 2019). D. McNamara was a member of the Colon Expert Group at the Medtronic session in Tarquinia. J.-C. Saurin has provided consultancy for Intromedic Capsovision Medtronic (2014-2018). C. Senore's department received PillCAM2 Colon devices from Medtronic to conduct a comparative study (2014-2017); along with C. Belissario and S. Minozzi, he also received consultancy fees from ESGE to provide methodological expertise (PICOs evaluation, literature searches, and evidence summaries) for the present project (2014-2017). S. Panter has received support for Ad boards from Medtronic (from 2010), for a capsule course from Diagmed (from 2005), and for training guideline development from the JAG training working group (from 2010). He was also a member of the Colon Expert Group at the Medtronic session in Tarquinia. C. Spada receives consultancy fees from Medtronic (2016 to present), and speakers and teaching fees and travel support from Olympus (2018-2019). R. Valori is a director of AnderVal Ltd., a company providing endoscopy skills training (2015 to present). B. D. Cash, D. Domagk, C. Hassan, H. Ivekovic, C. J. Rees, and M. Rutter have no competing interests.

References

[1] Rutter MD, Senore C, Bisschops R et al. The European Society of Gastrointestinal Endoscopy Quality Improvement Initiative: developing performance measures. Endoscopy 2016; 48: 81 - 89

[2] Liao Z, Gao R, Xu C et al. Indications and detection, completion, and retention rates of small-bowel capsule endoscopy: a systematic review. Gastrointest Endosc 2010; 71: $280-286$

[3] Pennazio M, Santucci R, Rondonotti E et al. Outcome of patients with obscure gastrointestinal bleeding after capsule endoscopy: report of 100 consecutive cases. Gastroenterology 2004; 126: 643-653

[4] Carey EJ, Leighton JA, Heigh RI et al. A single-center experience of 260 consecutive patients undergoing capsule endoscopy for obscure gastrointestinal bleeding. Am J Gastroenterol 2007; 102: 89-95

[5] Katsinelos P, Tziomalos K, Fasoulas K et al. Can capsule endoscopy be used as a diagnostic tool in the evaluation of nonbleeding indications in daily clinical practice? A prospective study. Med Princ Pract 2011; 20: $362-367$

[6] Bresci G, Parisi G, Bertoni M et al. The role of video capsule endoscopy for evaluating obscure gastrointestinal bleeding: usefulness of early use. J Gastroenterol 2005; 40: 256-259

[7] Singh A, Marshall C, Chaudhuri B et al. Timing of video capsule endoscopy relative to overt obscure GI bleeding: implications from a retrospective study. Gastrointest Endosc 2013; 77: 761 - 766 
[8] Kim SH, Keum B, Chun H] et al. Efficacy and implications of a 48-h cutoff for video capsule endoscopy application in overt obscure gastrointestinal bleeding. Endosc Int Open 2015; 3: E334-E348

[9] Pennazio M, Spada C, Eliakim R et al. Small-bowel capsule endoscopy and device-assisted enteroscopy for diagnosis and treatment of small-bowel disorders: European Society of Gastrointestinal Endoscopy (ESGE) Clinical Guideline. Endoscopy 2015; 47: 352 - 376

[10] Rondonotti E, Spada C, Adler S et al. Small-bowel capsule endoscopy and device-assisted enteroscopy for diagnosis and treatment of small-bowel disorders: European Society of Gastrointestinal Endoscopy (ESGE) Technical Review. Endoscopy 2018; 50: 423-446

[11] Fisher L, Lee Krinsky M, Anderson MA et al. The role of endoscopy in the management of obscure GI bleeding. Gastrointest Endosc 2010; 72: $471-479$

[12] Kaminski MF, Thomas-Gibson S, Bugajski M et al. Performance measures for lower gastrointestinal endoscopy: a European Society of Gastrointestinal Endoscopy (ESGE) Quality Improvement Initiative. Endoscopy 2017; 49: $378-397$

[13] Belsey J, Crosta C, Epstein O et al. Meta-analysis: efficacy of small bowel preparation for small bowel video capsule endoscopy. Curr Med Res Opin 2012; 28: $1883-1890$

[14] Kotwal VS, Attar BM, Gupta S et al. Should bowel preparation, antifoaming agents, or prokinetics be used before video capsule endoscopy? A systematic review and meta-analysis. Eur J Gastroenterol Hepatol 2014; 26: $137-145$

[15] Koulaouzidis A, Giannakou A, Yung DE et al. Do prokinetics influence the completion rate in small-bowel capsule endoscopy? A systematic review and meta-analysis. Curr Med Res Opin 2013; 29: 1171-1185

[16] Rokkas T, Papaxoinis K, Triantafyllou K et al. Does purgative preparation influence the diagnostic yield of small bowel video capsule endoscopy? A meta-analysis. Am J Gastroenterol 2009; 104: 219 227

[17] Wu L, Cao Y, Liao C et al. Systematic review and meta-analysis of randomized controlled trials of Simethicone for gastrointestinal endoscopic visibility. Scand J Gastroenterol 2011; 46: 227-235

[18] Rosa B], Barbosa M, Magalhaes J et al. Oral purgative and simethicone before small bowel capsule endoscopy. World J Gastrointest Endosc 2013; 5: 67-73

[19] Maqboul N, Murugananthan AU, Hong TP et al. Prep, no prep or more prep? A prospective randomised blinded study comparing two bowel preparation regimes with no preparation on quality of capsule endoscopy. Gastrointest Endosc 2012; 75: AB267

[20] Hansel SL, Gostout C], Murray JA et al. Assessment of combined bowel preparation for capsule endoscopy: A prospective randomized controlled study. Gastrointest Endosc 2014; 79: AB209

[21] Lapalus MG, Ben Soussan E, Saurin JC et al. Capsule endoscopy and bowel preparation with oral sodium phosphate: a prospective randomized controlled trial. Gastrointest Endosc 2008; 67: 1091-1096

[22] Niv E, Ovadia B, Ron Y et al. Ensure preparation and capsule endoscopy: a two-center prospective study. World J Gastroenterol 2013; 19: $1264-1270$

[23] Nouda S, Morita E, Kuramoto T et al. Usefulness of polyethylene glycol solution for bowel preparation before capsule endoscopy in patients with obscure gastrointestinal bleeding. Gastrointest Endosc 2010; 71: AB367

[24] Postgate A, Tekkis P, Patterson N et al. Are bowel purgatives and prokinetics useful for small-bowel capsule endoscopy? A prospective randomized controlled study. Gastrointest Endosc 2009; 69: 1120 1128

[25] Rayner-Hartley E, Cramer P, Cheong-Lee C et al. Comparison of moviprep, pico-salax and overnight fast in small bowel capsule endoscopy preparation. Gastrointest Endosc 2014; 79: AB210
[26] Spada C, Riccioni ME, Familiari P et al. Polyethylene glycol plus simethicone in small-bowel preparation for capsule endoscopy. Dig Liver Dis 2010; 42: $365-370$

[27] Tan K, Croft M, Francis G et al. Improve diagnostic yield of capsule endoscopy after bowel preparation: A prospective, randomised, controlled study. J Gastroenterol Hepatol 2010; 25: (Suppl. 03): A42

[28] van Tuyl SA, den Ouden H, Stolk MF et al. Optimal preparation for video capsule endoscopy: a prospective, randomized, single-blind study. Endoscopy 2007; 39: 1037-1040

[29] Viazis N, Sgouros S, Papaxoinis K et al. Bowel preparation increases the diagnostic yield of capsule endoscopy: a prospective, randomized, controlled study. Gastrointest Endosc 2004; 60: 534- 538

[30] Wei W, Ge ZZ, Lu H et al. Effect of mosapride on gastrointestinal transit time and diagnostic yield of capsule endoscopy. J Gastroenterol Hepatol 2007; 22: 1605-1608

[31] Wei W, Ge ZZ, Lu H et al. Purgative bowel cleansing combined with simethicone improves capsule endoscopy imaging. Am J Gastroenterol 2008; 103: 77-82

[32] Wi JH, Moon JS, Choi MG et al. Bowel preparation for capsule endoscopy: a prospective randomized multicenter study. Gut Liver 2009; 3: $180-185$

[33] Gkolfakis P, Tziatzios G, Dimitriadis GD et al. Meta-analysis of randomized controlled trials challenging the usefulness of purgative preparation before small-bowel video capsule endoscopy. Endoscopy 2018; 50: $671-668$

[34] Ching HL, Healy A, Thurston V et al. Upper gastrointestinal tract capsule endoscopy using a nurse-led protocol: First reported experience. World J Gastroenterol 2018; 24: 2893-2901

[35] Krijbolder MS, Grooteman KV, Bogers SK et al. Addition of simethicone improves small bowel capsule endoscopy visualisation quality. Neth J Med 2018; 76: 27-31

[36] Zhu SG, Qian YY, Tang XY et al. Gastric preparation for magnetically controlled capsule endoscopy: A prospective, randomized singleblinded controlled trial. Dig Liver Dis 2018; 50: 42 - 47

[37] Chen HB, Lian-Xiang P, Yue $\mathrm{H}$ et al. Randomized controlled trial of 3 days fasting and oral senna, combined with mannitol and simethicone, before capsule endoscopy. Medicine (Baltimore) 2017; 96: e8322

[38] Zhou J, Tang X, Wang J et al. Feasibility of a novel low-volume and sodium phosphate-free bowel preparation regimen for colon capsule endoscopy. Exp Ther Med 2017; 14: 1739-1743

[39] Hong-Bin C, Yue H, Chun H et al. Randomized controlled trial of cholestyramine and hydrotalcite to eliminate bile for capsule endoscopy. Saudi J Gastroenterol 2016; 22: 122-126

[40] Song HJ, Moon JS, Shim KN. Optimal bowel preparation for video capsule endoscopy. Gastroenterol Res Pract 2016; 2016: 6802810

[41] Argüelles-Arias F, Donat E, Fernández-Urien I et al. Guideline for wireless capsule endoscopy in children and adolescents: A consensus document by the SEGHNP (Spanish Society for Pediatric Gastroenterology, Hepatology, and Nutrition) and the SEPD (Spanish Society for Digestive Diseases). Rev Esp Enferm Dig 2015; 107: 714 - 731

[42] Papamichael K, Karatzas P, Theodoropoulos I et al. Simethicone adjunct to polyethylene glycol improves small bowel capsule endoscopy imaging in non-Crohn's disease patients. Ann Gastroenterol 2015; 28: $464-468$

[43] Oliva S, Cucchiara S, Spada C et al. Small bowel cleansing for capsule endoscopy in paediatric patients: a prospective randomized singleblind study. Dig Liver Dis 2014; 46: 51 - 55

[44] Friedrich K, Gehrke S, Stremmel W et al. First clinical trial of a newly developed capsule endoscope with panoramic side view for small bowel: a pilot study. J Gastroenterol Hepatol 2013; 28: 1496-1501

[45] Mathus-Vliegen E, Pellisé M, Heresbach D et al. Consensus guidelines for the use of bowel preparation prior to colonic diagnostic proce- 
dures: colonoscopy and small bowel video capsule endoscopy. Curr Med Res Opin 2013; 29: 931 - 945

[46] Song HJ, Moon JS, Do JH et al. Guidelines for bowel preparation before video capsule endoscopy. Clin Endosc 2013; 46: 147-154

[47] Chen HB, Huang Y, Chen SY et al. Small bowel preparations for capsule endoscopy with mannitol and simethicone: a prospective, randomized, clinical trial. J Clin Gastroenterol 2011; 45: 337-341

[48] Keeratichananont S, Sobhonslidsuk A, Kitiyakara T et al. The role of liquid simethicone in enhancing endoscopic visibility prior to esophagogastroduodenoscopy (EGD): A prospective, randomized, double-blinded, placebo-controlled trial. J Med Assoc Thai 2010; 93: $892-897$

[49] Fang YH, Chen CX, Zhang BL. Effect of small bowel preparation with simethicone on capsule endoscopy. J Zhejiang Univ Sci B 2009; 10: $46-51$

[50] Esaki M, Matsumoto T, Kudo T et al. Bowel preparations for capsule endoscopy: a comparison between simethicone and magnesium citrate. Gastrointest Endosc 2009; 69: 94-101

[51] Enns R. Capsule endoscopy: in search of the ideal image. Am J Gastroenterol 2008; 103: 83-85

[52] Wei W, Ge ZZ, Lu H et al. Purgative bowel cleansing combined with simethicone improves capsule endoscopy imaging. Am J Gastroenterol 2008; 103: 77-82

[53] Shiotani A, Opekun AR, Graham DY. Visualization of the small intestine using capsule endoscopy in healthy subjects. Dig Dis Sci 2007; 52: $1019-1025$

[54] Ge ZZ, Chen HY, Gao Y] et al. The role of simeticone in small-bowel preparation for capsule endoscopy. Endoscopy 2006; 38: 836-840

[55] Albert ], Göbel CM, Lesske J et al. Simethicone for small bowel preparation for capsule endoscopy: a systematic, single-blinded, controlled study. Gastrointest Endosc 2004; 59: 487-491

[56] Ponte A, Pinho R, Rodrigues A et al. Review of small-bowel cleansing scales in capsule endoscopy: A panoply of choices. World J Gastrointest Endosc 2016; 8: 600-609

[57] Park SC, Keum B, Hyun J] et al. A novel cleansing score system for capsule endoscopy. World J Gastroenterol 2010; 16: 875-880

[58] Brotz C, Nandi N, Conn M et al. A validation study of 3 grading systems to evaluate small-bowel cleansing for wireless capsule endoscopy: a quantitative index, a qualitative evaluation, and an overall adequacy assessment. Gastrointest Endosc 2009; 69: 262 - 270

[59] Van Weyenberg SJ, De Leest HT, Mulder C]. Description of a novel grading system to assess the quality of bowel preparation in video capsule endoscopy. Endoscopy 2011; 43: 406-411

[60] Klein A, Gizbar M, Bourke M] et al. Validated computed cleansing score for video capsule endoscopy. Dig Endosc 2016; 28: 564- 569

[61] Rezapour M, Amadi C, Gerson L. Retention associated with video capsule endoscopy: systematic review and meta-analysis. Gastrointest Endosc 2017; 85: 1157-1168.e2

[62] Calabrese C, Liguori G, Gionchetti P et al. Obscure gastrointestinal bleeding: single centre experience of capsule endoscopy. Intern Emerg Med 2013; 8: 681-687

[63] Carlo JT, DeMarco D, Smith BA et al. The utility of capsule endoscopy and its role for diagnosing pathology in the gastrointestinal tract. Am J Surg 2005; 190: $886-890$

[64] Cobrin GM, Pittman RH, Lewis BS. Increased diagnostic yield of small bowel tumors with capsule endoscopy. Cancer 2006; 107: 22-27

[65] Cuyle PJ, Schoofs N, Bossuyt P et al. Single-centre experience on use of videocapsule endoscopy for obscure gastrointestinal bleeding in 120 consecutive patients. Acta Gastroenterol Belg 2011; 74: 400 406
[66] Enns R, Go K, Chang H et al. Capsule endoscopy: a single-centre experience with the first 226 capsules. Can J Gastroenterol 2004; 18: $555-558$

[67] Estevez E, Gonzalez-Conde B, Vazquez-Iglesias JL et al. Diagnostic yield and clinical outcomes after capsule endoscopy in 100 consecutive patients with obscure gastrointestinal bleeding. Eur J Gastroenterol Hepatol 2006; 18: $881-888$

[68] Fidder HH, Nadler M, Lahat A et al. The utility of capsule endoscopy in the diagnosis of Crohn's disease based on patient's symptoms. J Clin Gastroenterol 2007; 41: 384-387

[69] Fireman Z, Eliakim R, Adler S et al. Capsule endoscopy in real life: A four-centre experience of 160 consecutive patients in Israel. Eur J Gastroenterol Hepatol 2004; 16: 927-931

[70] Goenka MK, Majumder S, Kumar S et al. Single center experience of capsule endoscopy in patients with obscure gastrointestinal bleeding. World J Gastroenterol 2011; 17: 774-778

[71] Holleran GE, Barry SA, Thornton O] et al. The use of small bowel capsule endoscopy in iron deficiency anaemia: low impact on outcome in the medium term despite high diagnostic yield. Eur J Gastroenterol Hepatol 2013; 25: 327-332

[72] Kalantzis N, Papanikolaou IS, Giannakoulopoulou E et al. Capsule endoscopy: the cumulative experience from its use in 193 patients with suspected small bowel disease. Hepatogastroenterology 2005; 52: $414-419$

[73] Kalla R, McAlindon ME, Drew K et al. Clinical utility of capsule endoscopy in patients with Crohn's disease and inflammatory bowel disease unclassified. Eur J Gastroenterol Hepatol 2013; 25: 706 - 713

[74] Katsinelos P, Fasoylas K, Chatzimavroudis G et al. Diagnostic yield and clinical management after capsule endoscopy in daily clinical practice: A single-center experience. Hippokratia 2010; 14: 271-276

[75] Kav T, Shorbagi Al, Sivri B et al. Clinical utility of capsule endoscopy in small intestinal diseases, experience of single referral center with 125 cases. Prz Gastroenterol 2009; 4: $245-250$

[76] Khan MI, Johnston M, Cunliffe R et al. The role of capsule endoscopy in small bowel pathology: a review of 122 cases. N Z Med J 2013; 126: $16-26$

[77] Kim JB, Ye BD, Song Y et al. Frequency of rebleeding events in obscure gastrointestinal bleeding with negative capsule endoscopy. J Gastroenterol Hepatol 2013; 28: 834-840

[78] Koulaouzidis A, Yung DE, Lam JH et al. The use of small-bowel capsule endoscopy in iron-deficiency anemia alone; be aware of the young anemic patient. Scand J Gastroenterol 2012; 47: 1094-1100

[79] Lim Y], Lee OY, Jeen YT et al. Indications for detection, completion, and retention rates of small bowel capsule endoscopy based on the 10-year data from the Korean Capsule Endoscopy Registry. Clin Endosc 2015; 48: 399-404

[80] Maieron A, Hubner D, Blaha B et al. Multicenter retrospective evaluation of capsule endoscopy in clinical routine. Endoscopy 2004; 36: $864-868$

[81] Matas JL, Asteinza M, Loscos JM et al. Diagnostic yield and safety of capsule endoscopy. Rev Esp Enferm Dig 2006; 98: 666 - 673

[82] Mehdizadeh S, Chen GC, Barkodar L et al. Capsule endoscopy in patients with Crohn's disease: diagnostic yield and safety. Gastrointest Endosc 2010; 71: 121-127

[83] Muhammad A, Pitchumoni CS. Evaluation of iron deficiency anemia in older adults: The role of wireless capsule endoscopy. J Clin Gastroenterol 2009; 43: 627-631

[84] Mussetto A, Fuccio L, Dari S et al. MiroCam capsule for obscure gastrointestinal bleeding: a prospective, single centre experience. Dig Liver Dis 2013; 45: $124-128$

[85] Pongprasobchai S, Chitsaeng S, Tanwandee T et al. Yield, etiologies and outcomes of capsule endoscopy in Thai patients with obscure 
gastrointestinal bleeding. World J Gastrointest Endosc 2013; 5: 122 127

[86] Qvigstad G, Hatlen-Rebhan P, Brenna E et al. Capsule endoscopy in clinical routine in patients with suspected disease of the small intestine: a 2-year prospective study. Scand J Gastroenterol 2006; 41: $614-618$

[87] Riccioni ME, Urgesi R, Spada C et al. Unexplained iron deficiency anaemia: Is it worthwhile to perform capsule endoscopy? Dig Liver Dis 2010; 42: $560-566$

[88] Rondonotti E, Soncini M, Girelli C et al. Small bowel capsule endoscopy in clinical practice: A multicenter 7-year survey. Eur J Gastroenterol Hepatol 2010; 22: 1380-1386

[89] Saul C, Torresini RJS, Teixeira CR et al. Avarage gastrointestinal bleeding and other indications of capsule endoscopy examination with the: Results in a consecutive series of 187 patients. GED Gastrentologia Endosc Dig 2010; 29: 109 - 117

[90] Sturniolo GC, Di Leo V, Vettorato MG et al. Small bowel exploration by wireless capsule endoscopy: Results from 314 procedures. Am J Med 2006; 119: 341 - 347

[91] Tatar EL, Shen EH, Palance AL et al. Clinical utility of wireless capsule endoscopy: experience with 200 cases. J Clin Gastroenterol 2006; 40: $140-144$

[92] Toy E, Rojany M, Sheikh R et al. Capsule endoscopy's impact on clinical management and outcomes: a single-center experience with 145 patients. Am J Gastroenterol 2008; 103: $3022-3028$

[93] Tukey M, Pleskow D, Legnani P et al. The utility of capsule endoscopy in patients with suspected Crohn's disease. Am J Gastroenterol 2009; 104: $2734-2739$

[94] van Turenhout ST, Jacobs MA, van Weyenberg SJ et al. Diagnostic yield of capsule endoscopy in a tertiary hospital in patients with obscure gastrointestinal bleeding. J Gastrointest Liver Dis 2010; 19: 141 - 145

[95] Van Tuyl SA, Van Noorden JT, Kuipers EJ et al. Results of videocapsule endoscopy in 250 patients with suspected small bowel pathology. Dig Dis Sci 2006; 51: $900-905$

[96] Yazici C, Losurdo J, Brown MD et al. Inpatient capsule endoscopy leads to frequent incomplete small bowel examinations. World J Gastroenterol 2012; 18: $5051-5057$

[97] Zagorowicz ES, Pietrzak AM, Wronska E et al. Small bowel tumors detected and missed during capsule endoscopy: single center experience. World J Gastroenterol 2013; 19: 9043 -9048

[98] Zhang BL, Fang YH, Chen CX et al. Single-center experience of 309 consecutive patients with obscure gastrointestinal bleeding. World J Gastroenterol 2009; 15: 5740-5745

[99] Fireman Z, Friedman S. Diagnostic yield of capsule endoscopy in obscure gastrointestinal bleeding. Digestion 2004; 70: 201 - 206

[100] Kav T, Bayraktar Y. Five years' experience with capsule endoscopy in a single center. World J Gastroenterol 2009; 15: 1934-1942

[101] Koulaouzidis A, Rondonotti E, Giannakou A et al. Diagnostic yield of small-bowel capsule endoscopy in patients with iron-deficiency anemia: a systematic review. Gastrointest Endosc 2012; 76: $983-992$

[102] Saurin JC, Delvaux M, Gaudin JL et al. Diagnostic value of endoscopic capsule in patients with obscure digestive bleeding: blinded comparison with video push-enteroscopy. Endoscopy 2003; 35: 576 584

[103] Korman LY, Delvaux M, Gay G et al. Capsule endoscopy structured terminology (CEST): proposal of a standardized and structured terminology for reporting capsule endoscopy procedures. Endoscopy 2005; 37: 951 - 959

[104] Delvaux M, Friedman S, Keuchel M et al. Structured terminology for capsule endoscopy: results of retrospective testing and validation in 766 small-bowel investigations. Endoscopy 2005; 37: 945 - 950

[105] Jang BI, Lee SH, Moon JS et al. Inter-observer agreement on the interpretation of capsule endoscopy findings based on capsule endoscopy structured terminology: a multicenter study by the Korean Gut Image Study Group. Scand J Gastroenterol 2010; 45: 370 374

[106] Pezzoli A, Cannizzaro R, Pennazio M et al. Interobserver agreement in describing video capsule endoscopy findings: a multicentre prospective study. Dig Liver Dis 2011; 43: 126-131

[107] Postgate A, Haycock A, Thomas-Gibson S et al. Computer-aided learning in capsule endoscopy leads to improvement in lesion recognition ability. Gastrointest Endosc 2009; 70: 310-316

[108] Dias de Castro F, Magalhães ], Boal Carvalho P et al. Improving diagnostic yield in obscure gastrointestinal bleeding - how virtual chromoendoscopy may be the answer. Eur J Gastroenterol Hepatol 2015; 27: $735-740$

[109] Duque G, Almeida N, Figueiredo P et al. Virtual chromoendoscopy can be a useful software tool in capsule endoscopy. Rev Esp Enferm Dig 2012; 104: $231-236$

[110] Koulaouzidis A, Douglas S, Plevris JN. Blue mode does not offer any benefit over white light when calculating Lewis score in small bowel capsule endoscopy. World J Gastrointest Endosc 2012; 4: 33-37

[111] Kobayashi Y, Watabe H, Yamada A et al. Efficacy of flexible spectral imaging color enhancement on the detection of small intestinal diseases by capsule endoscopy. J Dig Dis 2012; 13: 614-620

[112] Maeda M, Hiraishi H. Efficacy of video capsule endoscopy with flexible spectral imaging color enhancement at setting 3 for differential diagnosis of red spots in the small bowel. Dig Endosc 2014; 26 : $228-231$

[113] Fernandez-Urien I, Carretero C, Gonzalez B et al. Incidence, clinical outcomes, and therapeutic approaches of capsule endoscopy-related adverse events in a large study population. Rev Esp Enferm Dig 2015; 107: $745-752$

[114] Al-Bawardy B, Locke G, Huprich JE et al. Retained capsule endoscopy in a large tertiary care academic practice and radiologic predictors of retention. Inflamm Bowel Dis 2015; 21: 2158-2164

[115] Cheon JH, Kim YS, Lee IS et al. Can we predict spontaneous capsule passage after retention? A nationwide study to evaluate the incidence and clinical outcomes of capsule retention. Endoscopy 2007; 39: $1046-1052$

[116] Philpott H, Allen B, Francis G et al. Experienced endoscopists interpret capsule endoscopy studies more accurately? A trainee study. J Gastroenterol Hepatol 2010; 25: A37-A38

[117] Rajan E, lyer PG, Oxentenko AS et al. Training in small-bowel capsule endoscopy: Assessing and defining competency. Gastrointest Endosc 2013; 78: 617-622

[118] Alakkari A, El-Sherif O, Dobson M et al. Is focused training adequate or is prior endoscopy experience needed for reliable capsule endoscopy reporting? J Gastroenterol Hepatol 2013; 2: 628 - 631

[119] Albert JG, Humbla O, McAlindon ME et al. Simple evaluation tool (ET(ET) indicates increase of diagnostic skills from small bowel capsule endoscopy training courses: a prospective observational European multicenter study. Medicine (Baltimore) 2015; 94: e1941

[120] Monkemuller K, Neumann H, Meyer F et al. A retrospective analysis of emergency double-balloon enteroscopy for small-bowel bleeding. Endoscopy 2009; 41: 715-717

[121] Chokshi RV, Hovis CE, Hollander T et al. Prevalence of missed adenomas in patients with inadequate bowel preparation on screening colonoscopy. Gastrointest Endosc 2012; 75: 1197-1203

[122] Lin MC, Chen PJ, Shih YL et al. Outcome and safety of anterograde and retrograde single-balloon enteroscopy: clinical experience at a tertiary medical center in Taiwan. PLoS One 2016; 11: e0161188

[123] Lenz P, Roggel M, Domagk D. Double- vs. single-balloon enteroscopy: single center experience with emphasis on procedural performance. Int J Colorectal Dis 2013; 28: 1239 - 1246 
[124] May A, Nachbar L, Ell C. Double-balloon enteroscopy (push-and-pull enteroscopy) of the small bowel: feasibility and diagnostic and therapeutic yield in patients with suspected small bowel disease. Gastrointest Endosc 2005; 62: 62-70

[125] Yamamoto H, Kita H, Sunada K et al. Clinical outcomes of doubleballoon endoscopy for the diagnosis and treatment of small-intestinal diseases. Clin Gastroenterol Hepatol 2004; 2: 1010-1016

[126] Hassan C, Bretthauer M, Kaminski MF et al. Bowel preparation for colonoscopy: European Society of Gastrointestinal Endoscopy (ESGE) guideline. Endoscopy 2013; 45: 142 - 150

[127] Johnson DA, Barkun AN, Cohen LB et al. Optimizing adequacy of bowel cleansing for colonoscopy: recommendations from the US multi-society task force on colorectal cancer. Gastroenterology 2014; 147: $903-924$

[128] Xin L, Gao Y, Liao Z et al. The reasonable calculation of complete enteroscopy rate for balloon-assisted enteroscopy. Endoscopy 2011; 43: 832

[129] Wadhwa V, Sethi S, Tewani S et al. A meta-analysis on efficacy and safety: single-balloon vs. double-balloon enteroscopy. Gastroenterol Rep (Oxf) 2015; 3: 148 - 155

[130] Lipka S, Rabbanifard R, Kumar A et al. Single versus double balloon enteroscopy for small bowel diagnostics: a systematic review and meta-analysis. J Clin Gastroenterol 2015; 49: 177-184

[131] Yamamoto H, Yano T, Ohmiya $\mathrm{N}$ et al. Double-balloon endoscopy is safe and effective for the diagnosis and treatment of small-bowel disorders: prospective multicenter study carried out by expert and non-expert endoscopists in Japan. Dig Endosc 2015; 27: 331 - 337

[132] Tee HP, How SH, Kaffes AJ. Learning curve for double-balloon enteroscopy: Findings from an analysis of 282 procedures. World J Gastrointest Endosc 2012; 4: 368-372

[133] Buscaglia JM, Okolo PI 3rd. Deep enteroscopy: training, indications, and the endoscopic technique. Gastrointest Endosc 2011; 73 : $1023-1028$

[134] Maclntosh D, Dubé C, Hollingworth R et al. The endoscopy Global Rating Scale-Canada: development and implementation of a quality improvement tool. Can J Gastroenterol 2013; 27: 74-82

[135] Sint Nicolaas J, de Jonge V, de Man RA et al. The Global Rating Scale in clinical practice: a comprehensive quality assurance programme for endoscopy departments. Dig Liver Dis 2012; 44: 919-924

[136] Aquino JCM, Bernardo WM, de Moura DTH et al. Carbon dioxide versus air insufflation enteroscopy: a systematic review and meta-analysis based on randomized controlled trials. Endosc Int Open 2018; 6: E637-E645

[137] Shiani A, Lipka S, Lai A et al. Carbon dioxide versus room air insufflation during balloon-assisted enteroscopy: A systematic review with meta-analysis. Endosc Int Open 2017; 5: E67-E75

[138] Nishizawa T, Suzuki H, Fujimoto $A$ et al. Effects of carbon dioxide insufflation in balloon-assisted enteroscopy: A systematic review and meta-analysis. United European Gastroenterol J 2016; 4: 11 - 17 